\section{ESTUDIO PRELIMINAR DE LOS GRABADOS RUPES- TRES DE LA CUEVA DEL MORO (TARIFA, CÁDIZ) Y EL ARTE PALEOLÍTICO DEL CAMPO DE GIBRALTAR}

\author{
PRELIMINARY STUDY OF THE ROCK \\ ART ENGRAVINGS OF THE CAVE OF \\ THE MORO (TARIFA, CÁDIZ) AND THE \\ PALAEOLITHIC ROCK ART OF THE \\ CAMPO DE GIBRALTAR
}

\author{
MARTÍ MAS CORNELLÀ \\ SERGIO RIPOLL LÓPEZ (*) \\ JUAN ANTONIO MARTOS ROMERO \\ JOSÉ PABLO PANIAGUA PÉREZ \\ JOSÉ RAMÓN LÓPEZ MORENO DE \\ REDROJO (**) \\ LOTHAR BERGMANN (***)
}

\section{RESUMEN}

En la primavera de 1995 se produjo el descubrimiento de la Cueva del Moro con un conjunto de figuraciones grabadas de équidos con una filiación superopaleolítica indudable. Los numerosos hallazgos que se están produciendo desde hace unos años en la zona del Campo de Gibraltar nos indican que se trata de una área con una

(*) Codirectores del Proyecto de Documentación del Arte Paleolítico en el Campo de Gibraltar. Departamento de Prehistoria e Historia Antigua. Facultad de Geografía e Historia. Universidad Nacional de Educación a Distancia. Avda. Senda del Rey s/n, 28071 Madrid.

(**) Becarios predoctorales del Departamento de Prehistoria e Historia Antigua. Facultad de Geografía e Historia. Universidad Nacional de Educación a Distancia. Avda. Senda del Rey s/n, 28071 Madrid.

(***) Zona Arqueológica de la Ensenada de Bolonia.

Queremos agradecer a Lothar Bergmann su deferencia al habernos confiado el estudio científico de las representaciones paleolíticas por él halladas en la Cueva del Moro.

El artículo fue remitido en su versión final el 17-X-95. gran importancia y expectativas de estudio. Los hallazgos, tanto de arte rupestre como de cultura material, en estaciones al aire libre o en abrigos rocosos completan un panorama cada día más prometedor. Además este nuevo conjunto representa el arte rupestre paleolítico más meridional de Europa.

\footnotetext{
ABSTRACT

The spring of 1995 marked the discovery of the Cave of the Moro with a grout of horse engravings of undoubted Upper Palaeolithic date. The numerous other finds that have been made in recent years in the zone of the Campo de Gibraltar suggest that it is an area of great importance. Both the rock art and the material culture evidence, in the open air or in rock shelters, has continually increasing potential for study. Furthermore this group of sites represents the most southern Palaeolithic rock art in Europe.
} 
Palabras clave: Arte rupestre. Grabados. Campo de Gibraltar. Estaciones al aire libre. Solutrense.

Key words: Rock Art. Engravings. Campo de Gibraltar. Open air sites. Solutrean.

\section{INTRODUCCIÓN}

En abril de 1995 se produjo un importante hallazgo en las sierras del Campo de Gibraltar, en el término municipal de Tarifa (Cádiz) (Fig. 1), que por su interés creemos oportuno dar a conocer en este primer avance a su estudio. Durante la colaboración que mantiene Lothar Bergmann con la Delegación Provincial de la Consejería de Cultura en Cádiz en la realización del «Catálogo de Zonas Arqueológicas de la Ensenada de Bolonia», al objeto de su inclusión en el documento urbanístico «Plan Especial de Protección y Mejora de la Ensenada de Bolonia y Núcleo de El Lentiscal», se descubrió una nueva cavidad con pinturas y grabados. Desde el Conjunto Arqueológico de «Baelo Claudia» y a través de su director, José Castiñeira Sánchez, se contactó con los investigadores del proyecto:

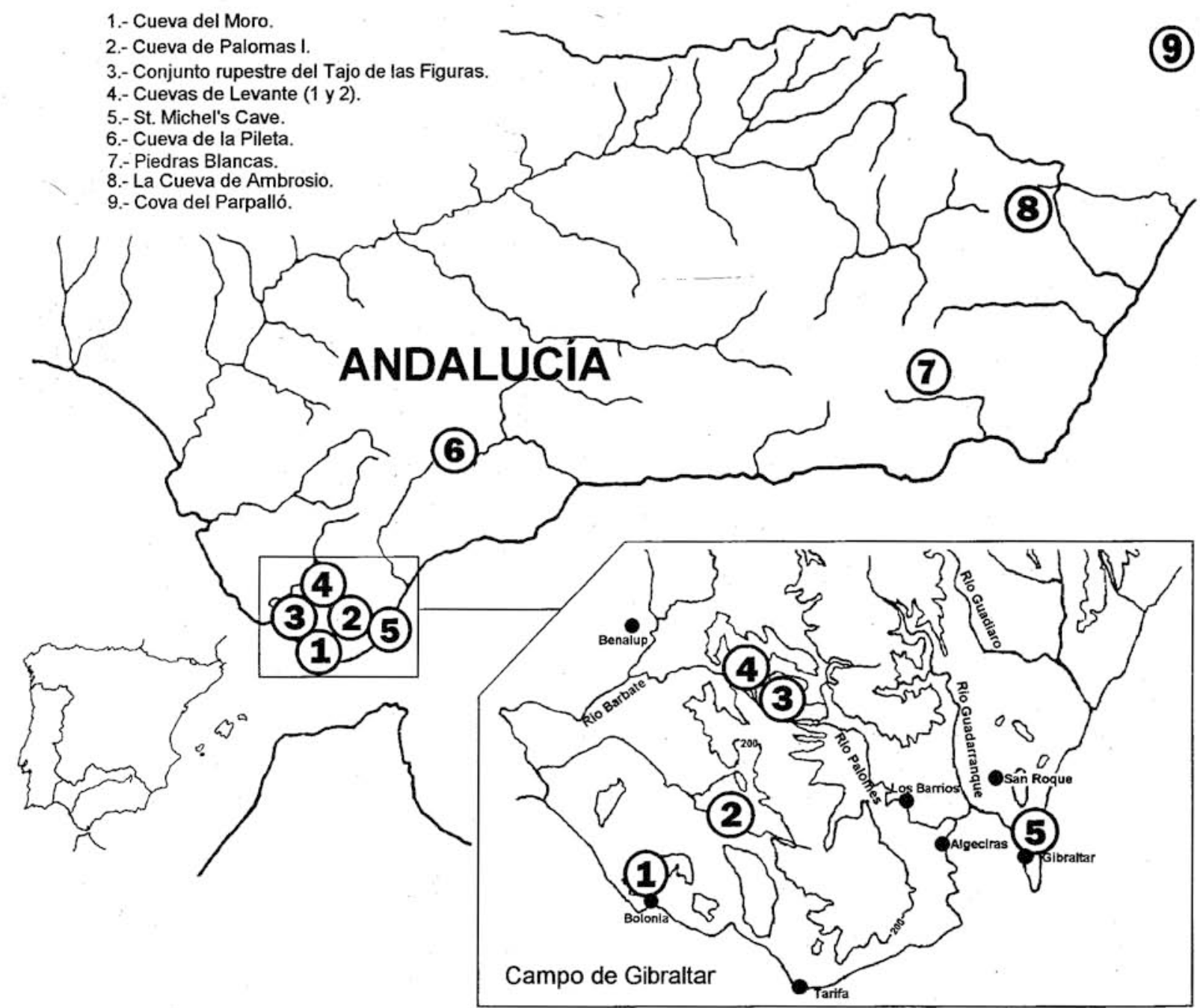

Fig. 1. Mapa en el que figuran los yacimientos con manifestaciones artísticas paleolíticas al aire libre o en abrigos rocosos de Andalucía citados en texto. Como puede observarse se concentran en las provincias de Cádiz (Campo de Gibraltar y sierras que bordean la antigua Laguna de la Janda) y Almería.

T. P., 52, n. $^{\circ} 2,1995$ 
«Las manifestaciones rupestres prehistóricas de la zona gaditana» (actividades arqueológicas autorizadas y subvencionadas por la Dirección General de Bienes Culturales de la Junta de Andalucía), que en colaboración con el Departamento de Prehistoria e Historia Antigua de la U.N.E.D. y otras instituciones vienen trabajando en la zona desde 1988 (Más Cornellá, 1993). Este proyecto contempla la prospección, documentación e investigación de los yacimientos con pinturas y grabados rupestres del Campo de Gibraltar, sierras que bordean la antigua Laguna de la Janda y áreas próximas algo más alejadas, así como su contexto arqueológico. En esta zona existen algo más de ciento veinte estaciones conocidas con manifestaciones artísticas postpaleolíticas, la mayoría de los cuales fueron dadas a conocer por J. Cabré y E. Hernández-Pacheco (1914), H. Breuil y M.C. Burkitt (1929), mientras que otras han sido divulgadas más recientemente (Más Cornellá et alii, 1995).

Debido a la importancia de la estación descubierta, los trabajos de reproducción, estudio directo y documentación se realizaron con toda urgencia (mayo de 1995), aunque el análisis definitivo deberá ser completado y revisado en futuras campañas.

\section{LA CUEVA DEL MORO}

La Cueva del Moro (Lám. I A), a pesar de su denominación se trata de una de las características cavidades o abrigos rocosos, originados por corrosión y erosión éblica, junto con superficies desgastadas en extensión, dando lugar en conjunto a una morfología de «tafonis» en areniscas silíceas como las que forman las sierras del Campo de Gibraltar ( «Formación Areniscas del Aljibe»). Estan constituidas por granos de cuarzo, bien redondeados, de tamaño pequeño a grueso, a veces conglomeráticas, con apenas matriz de limos y arenas de grano muy fino y mala cementación, de tipo ferruginoso, no muy consistentes, por lo que la roca tiene una cierta friabilidad. La «Formación Areniscas del Aljibe» llega a alcanzar una potencia de $2.000-1.500 \mathrm{~m}$. y está formada predominantemente por areniscas de aspecto masivo, que son exclusivamente silíceas y tienen una coloración blanquecina o amarillenta en fractura fresca, que pasa a parda por meteorización, con finas intercalaciones de materiales pelíticos de color marrón claro (Más Cornellá et alii, e.p.).

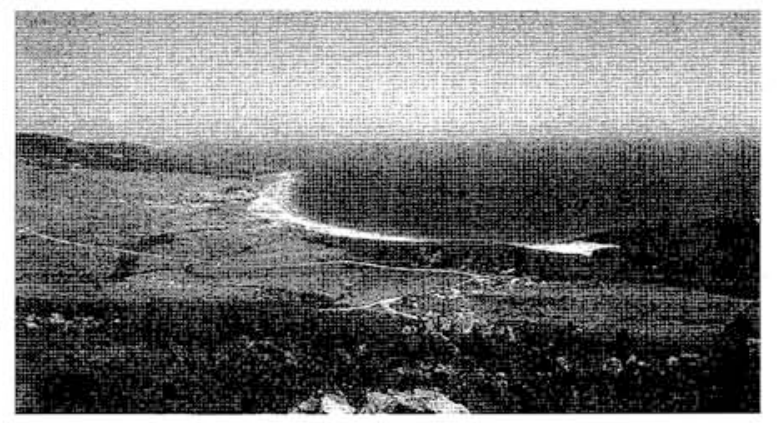

A

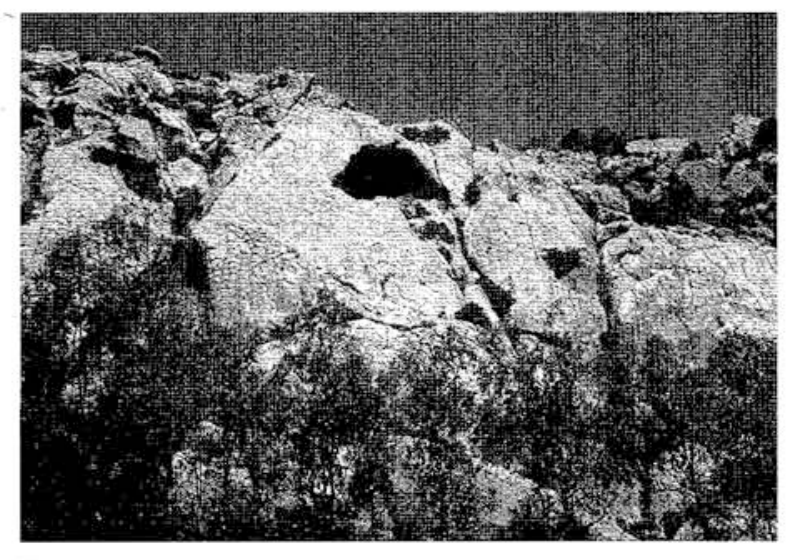

B

Lám. I A. Vista desde la Cueva del Moro. Su situación sobre el Estrecho de Gibraltar le confiere una posición privilegiada. B. Vista de la Sierra de la Plata donde se sitúa la Cueva del Moro.

El abrigo (Lám. I B) consta de dos pisos superpuestos y está situado sobre un escarpe rocoso de unos $40 \mathrm{~m}$. de altura. En la actualidad la cavidad está totalmente vacía de sedimento y no tenemos ningún dato para pensar que alguna vez hubiera tenido un depósito realmente importante. De cualquier forma, hoy en día, el piso está totalmente lavado. En el nivel inferior, al fondo del abrigo, se sitúan los dos paneles que contienen cuatro representaciones incisas de équidos. El surco de todas las figuras es bastante ancho y profundo llegando, en algún caso, a dar la sensación de bajo relieve. La línea del grabado se encuentra totalmente patinada y en 
ningún caso se nos han planteado dudas en cuanto a su autenticidad.

\section{Panel A}

Se encuentra localizado a $90 \mathrm{~cm}$. del suelo actual del abrigo y tiene unas dimensiones aproximadas de $380 \mathrm{~cm}$. de longitud por $90 \mathrm{~cm}$. de anchura. Morfológicamente, esta superficie tiende al rectángulo y posee un color rojo amarillento (HUE 5YR 5/6-6/8 según las tablas Munsell). Tiene una orientación general de $69^{\circ}$ Oeste y un buzamiento de $45^{\circ}$ Sur. En él se han documentado tres figuraciones naturalistas grabadas que representan dos «protomos» de équidos y una tercera figura, prácticamente completa, también de équido.

\section{Figura 1}

«Protomos» de équido (Lám. II A) que incluye los cuartos delanteros orientado hacia la izquierda $(45 \mathrm{~cm}$. de longitud por $40 \mathrm{~cm}$. de anchura y $38 \mathrm{~cm}$. de máxima entre paralelas con un buzamiento de $4^{\circ}$ Este). La figura se inicia con la línea cérvico dorsal a la altura del cuello, continúa hasta la nuca y a partir de este punto el autor aprovechó una grieta natural para completar el trazo grabado, realizando la frente y la testuz. No se representó la crinera, ni siquiera un esbozo de la misma. A la altura del morro, de tendencia cuadrangular, la incisión se prolonga, alejándose de la grieta para dar forma a una fuerte quijada que marca el barboquejo (Lám. II B). El resultado adopta el característico «pico de pato», convención estilística adscrita al Solutrense. La cabeza, que no presenta ningún detalle, como orejas, ojos.., está resuelta con unas proporciones bien equilibradas, consecuencia del perfecto dominio técnico y del buen acabado estilístico. El équido continúa con la línea del pecho que desemboca en las extremidades delanteras, apareciendo una sola pata claramente representada, resuelta en trazo doble, sin ningún tipo de despiece, salvo el casco que se correspondería con la extremidad derecha. De forma paralela, pero en una posición ligeramente más alta y faltando la parte inferior, perdida por erosión, también se distingue la otra pata, la izquierda, que se conforma a base de sendos trazos paralelos. La diferencia de posición de las patas podría indicarnos una cierta aplicación de la perspectiva. En el interior de la figura se observa una incisión $(9,5 \mathrm{~cm}$. de longitud), hori- zontal y perpendicular a la línea del pecho, siendo esta última anterior al trazo descrito, ya que se superpone a la misma.

El grabado de tipo lineal en «U», en todo su contorno, tiene una anchura media de $20 \mathrm{~mm}$. y, en la zona de la quijada, alcanza los $7 \mathrm{~mm}$. de profundidad, lo cual produce una sensación de volumen en toda la figura, siendo en la cabeza tan acentuado que podría llegar a confundirse con un relieve. En el resto de la figura la incisión es más somera $(<3 \mathrm{~mm}$.) y fina.

En cuanto al proceso de ejecución es destacable la ausencia aparente tanto de interrupciones como de líneas de fuga o correcciones, todo ello quizá sea consecuencia de la técnica utilizada para la realización del grabado o debido al soporte, cuyas características permiten una técnica depurada, sin rectificaciones. La perspectiva utilizada es el clásico perfil absoluto, ya que se representa únicamente una de las extremidades en primer plano junto con una pequeña aplicación de la perspectiva biangular en las extremidades anteriores. En conjunto, llama poderosamente la atención la gracilidad de esta figuración.

\section{Figura 2}

A la derecha de la figura anterior y a la altura donde terminaría su crinera, aparece un segundo «protomos» de équido dispuesto hacia la derecha y de dimensiones más reducidas (19 $\mathrm{cm}$. de longitud por $9 \mathrm{~cm}$. de anchura y $20 \mathrm{~cm}$. de máxima entre paralelas, con un buzamiento de $29^{\circ}$ Sur) (Lám III). Realizado en un solo trazo, sin interrupciones, el grabado se inicia en la base del cuello y, sin solución de continuidad, desciende hasta la nuca para formar una cabeza subrredondeada, que se presenta completa y sin ningún detalle. A la altura de la quijada aparece una inflexión que da lugar a una corta línea pectoral. La figura está representada en un perfil absoluto. El surco es de tipo lineal en «U» con una media de $17 \mathrm{~mm}$. de anchura máxima y 3 $\mathrm{mm}$. de profundidad. En cualquier caso, la sensación de relieve es menor a la del resto de las representaciones figuradas en el abrigo, bien debido a que el grabado se encuentra más perdido, bien a causa de la menor profundidad alcanzada por el trazo. Esta figuración, hallada durante el proceso de estudio de la cavidad, no posee la espectacularidad de las otras representaciones y únicamente es observable con una iluminación adecuada.

T. P., 52, n. ${ }^{\circ} 2,1995$ 
A
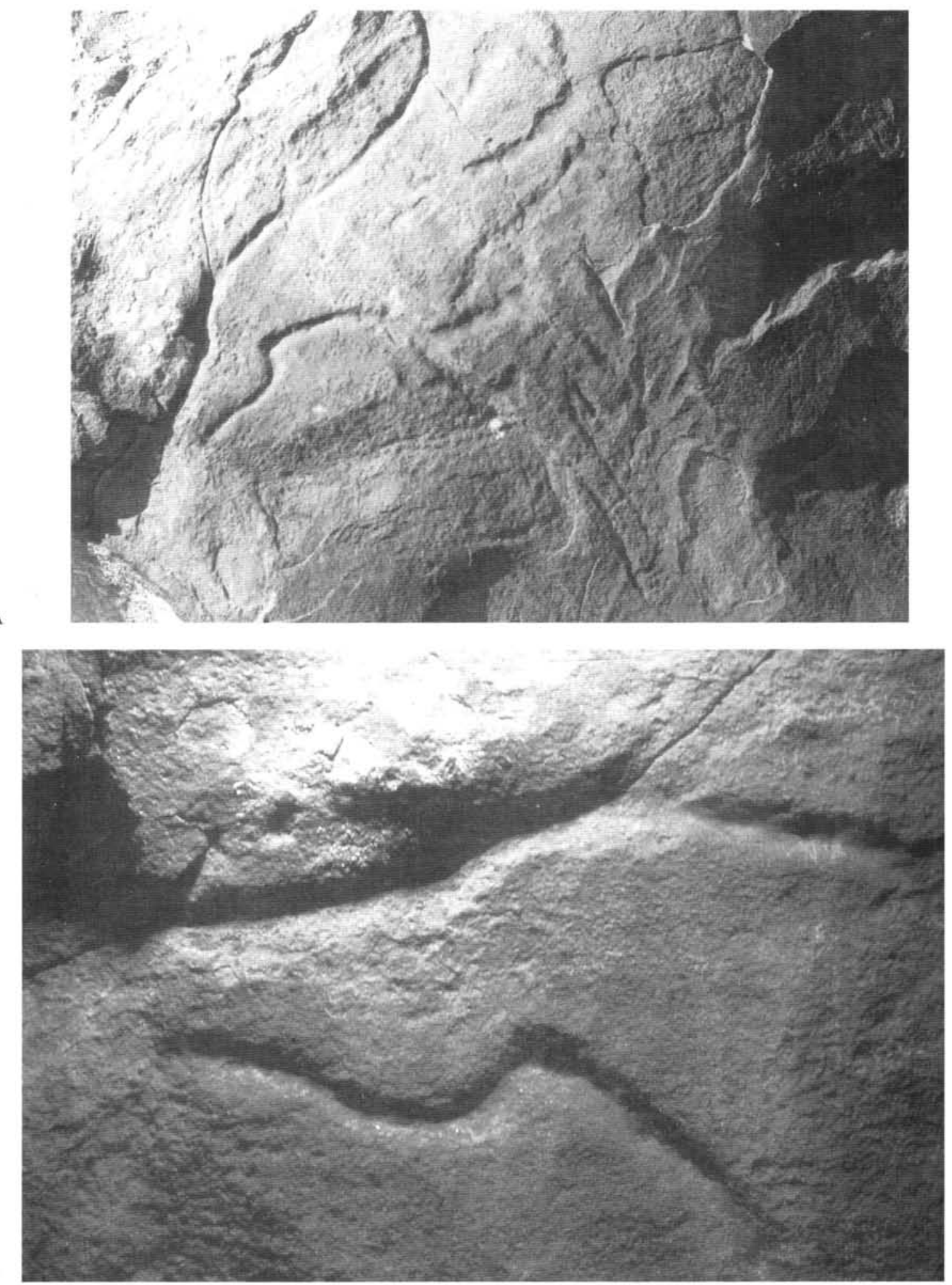

Lám. II A. Protomos de caballo grabado profundamente, descrito en el texto como figura 1 del panel A. Se halla a la izquierda del conjunto. B. Detalle de la cabeza de la figura 1. donde se aprecia claramente el contorno de la cabeza que en algún caso puede llegar a ser un bajo relieve.

T. P., 52, n. ${ }^{\circ} 2,1995$ 


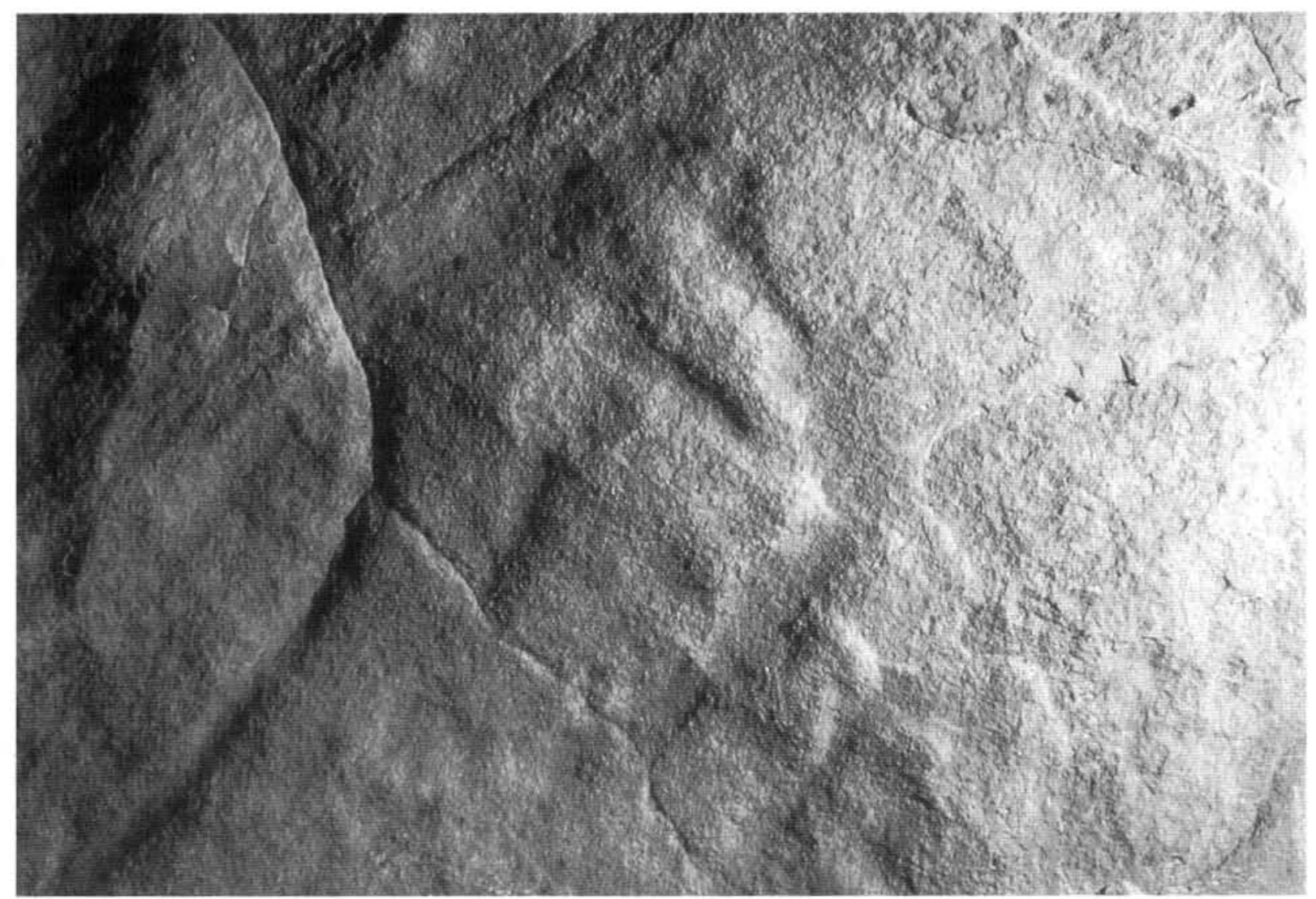

Lám. III. Protomos de équido (figura 2 del panel A), algo perdido por la erosión natural. Esta figura únicamente se aprecia con una iluminación adecuada.

\section{Figura 3}

Esta figura (Lám. IV), situada a la derecha de las anteriores y en un plano ligeramente superior, con un buzamiento distinto al de la roca soporte $\left(41^{\circ} \mathrm{W}\right)$, nos muestra una espléndida representación de équido prácticamente completa orientada hacia la izquierda $(108 \mathrm{~cm}$. de longitud por $77 \mathrm{~cm}$. de anchura y $106 \mathrm{~cm}$. de máxima entre paralelas con un buzamiento de $34^{\circ}$ Sur). Presenta una cabeza pequeña (Lám. V A) en relación al resto de la figura, con el barboquejo bastante destacado, adquiriendo la ya mencionada característica solutrense. La quijada está muy marcada (Lám. V B), casi en ángulo recto y a continuación el morro de morfología subredondeada da paso a la testuz y la frente, algo abombadas. Tras una pequeña inflexión aparece la crinera desdoblada y caída hacia atrás, de escaso recorrido y amplitud. No hay ningún detalle interior en la cabeza a excepción de dos trazos situados en la parte posterior y bajo la crinera que podrían representar la oreja izquierda. La línea cérvico dorsal se prolonga hasta la cola, corta y levantada, resuelta con dos trazos individuales, siendo uno de ellos continuación de la línea cérvico dorsal y el otro origen de los cuartos traseros. Parece querer representar una característica peculiar de este animal, ya que normalmente los caballos figurados en el arte pleistoceno poseen largas colas (Lám. VI A). En este punto la figura desaparece por un efracto natural de la roca, sin poderse determinar si, en su momento, figuraban los cuartos traseros en su totalidad. Se insinúan claramente el inicio de las nalgas y una parte de las patas traseras que al igual que las delanteras están grabadas en perspectiva torcida. Retomamos el trazo a la altura de la babilla desde donde arranca la línea del vientre mediante una incisión curva

T. P., 52, n. 2. 1995 


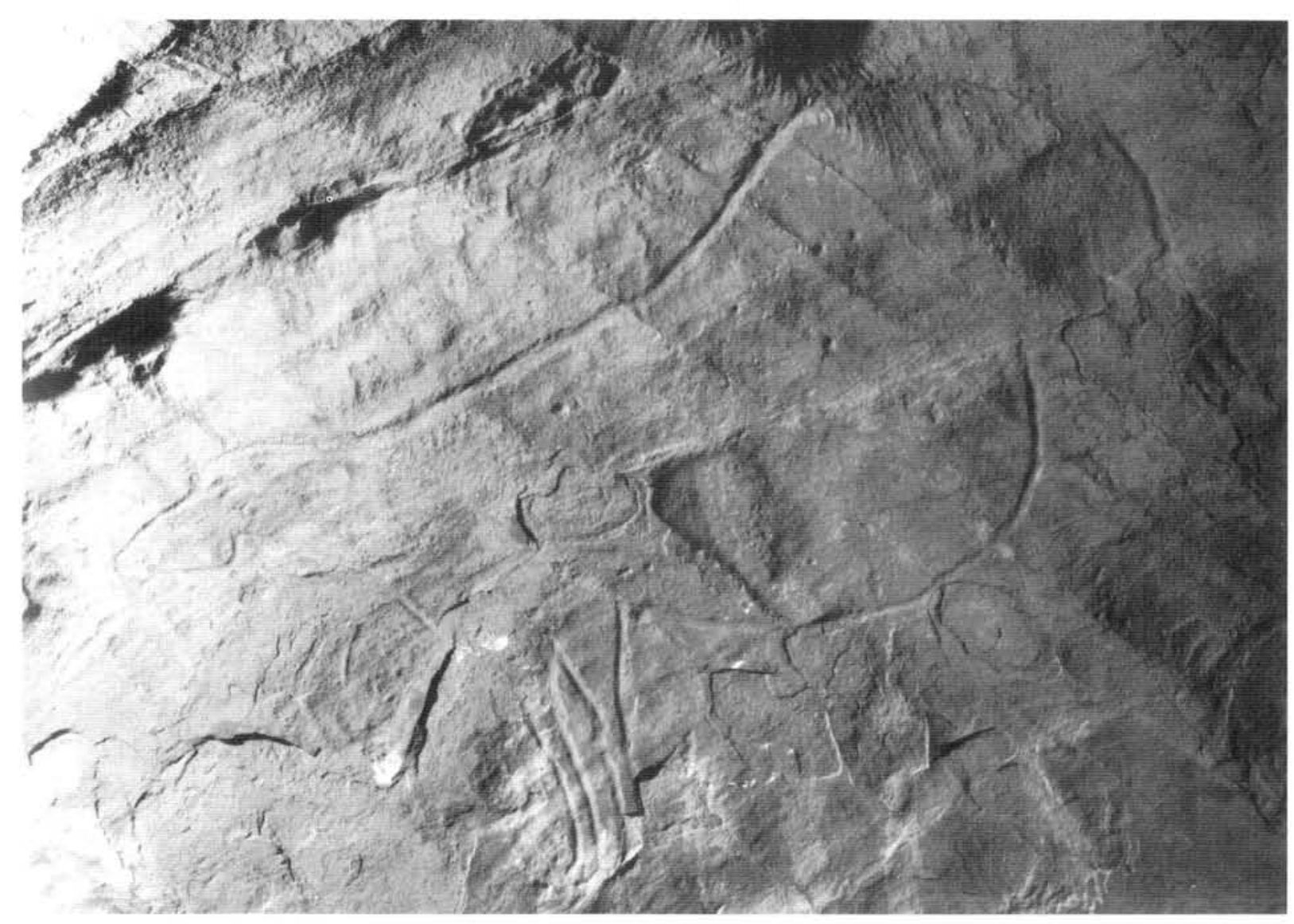

Lám. IV. Vista de conjunto del gran équido casi completo (figura 3 panel A). Se distingue bien el vientre abultado así como la cabeza y los cuartos anteriores.

continuada muy pronunciada. Seguidamente los cuartos delanteros se representan individualizando las dos patas con un trazo doble (Lám. VI B). La pata izquierda no aparece cerrada debido a un desconchón en la zona del casco, pieza que encontramos al pie de la representación y que encajaba perfectamente en su lugar. Dicho elemento ha sido entregado a la Dirección del Conjunto Arqueológico de «Baelo Claudia», para ser depositado en el Museo de Cádiz, con la finalidad de que en un futuro próximo pueda restaurarse la figura y devolverle al conjunto su aspecto original o ser utilizado, si en un determinado momento se cree oportuno, para posibles dataciones directas. Al documentar el motivo algunas de las fotos se realizaron restituyendo este elemento. Por otro lado, la pata derecha aparece completa presentando el despiece del casco. En realidad su apariencia es más de pezuña que de casco, ya que morfológicamente se prolonga hacia adelante. La línea del pecho es continuación de esta última pata hasta su unión con la quijada.

Está realizada con un grabado de tipo lineal en «U» con una anchura media de $11 \mathrm{~mm}$. y una profundidad que en muchas zonas alcanza los 4 mm. La sensación de volumen en este caso es menos acusada, destacando más en la cabeza, quizá por su menor tamaño. Es evidente que existe una gran desproporción entre la cabeza y las extremidades delanteras y el resto del cuerpo. El esquema de realización es semejante al de la figura 1, resolviéndose en un solo trazo que sólo se interrumpe a la altura de la cola. En la transición de la pata delantera al cuello, el borde interior del grabado aparece muy perdido, sin poderse precisar si se debe a una modificación en la técnica o a alteraciones producidas por 


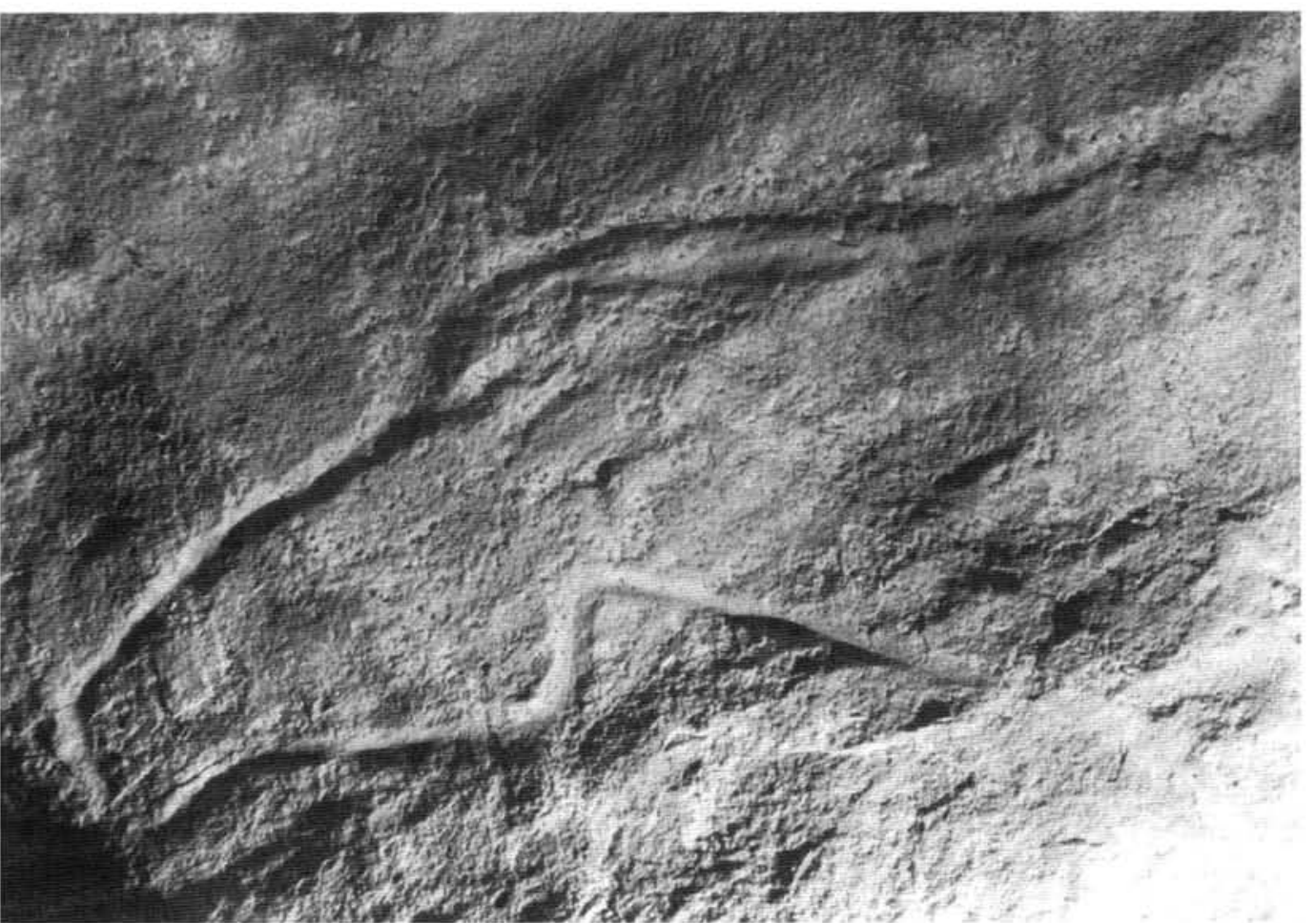

A

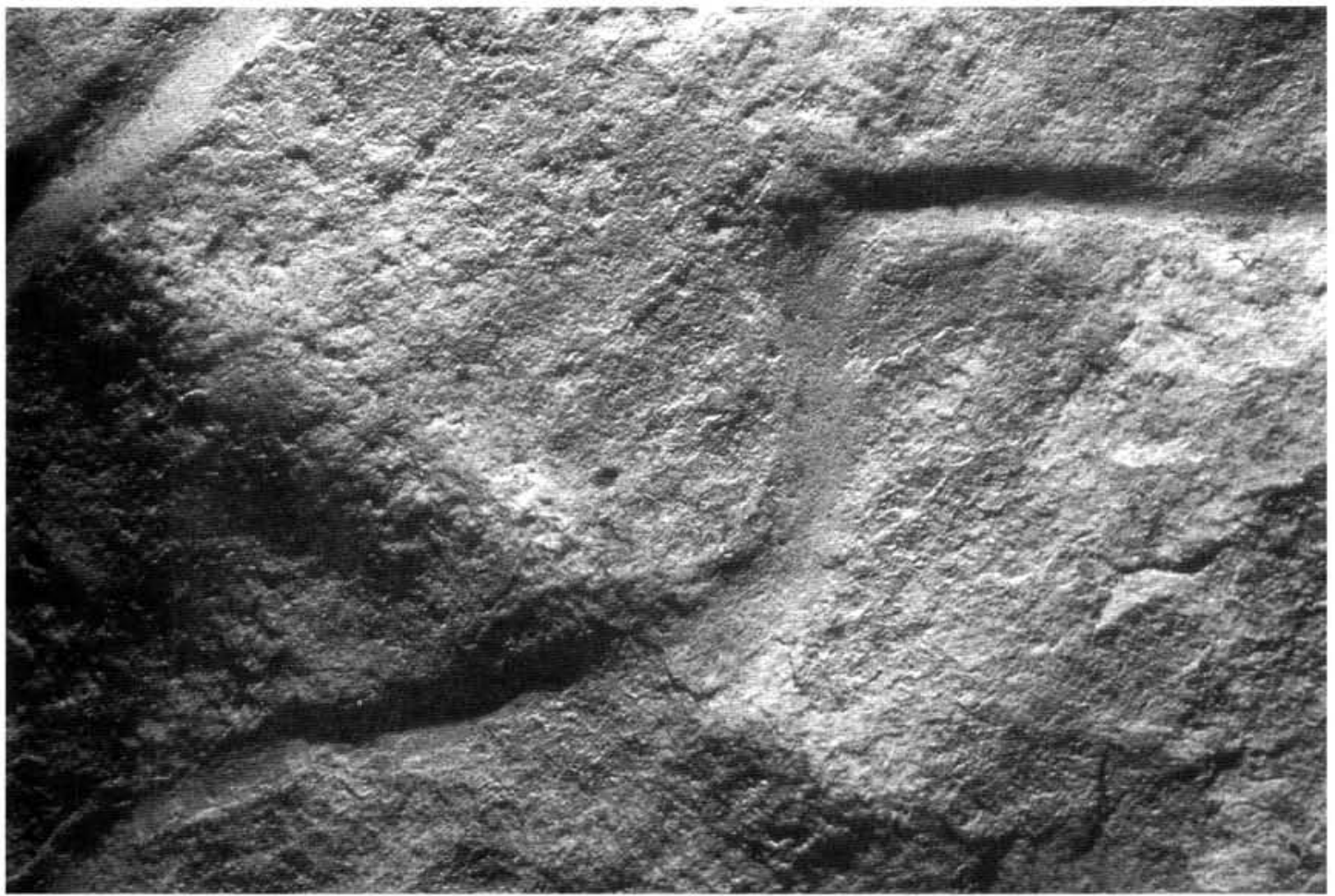

Lám. V A. Detalle de la cabeza del gran équido (figura 3 panel A). La crinera simplemente está esbozada al igual que la oreja. B. Un detalle muy ampliado de la inflexión de la quijada en la que también se puede apreciar la técnica utilizada para realizar el grabado.

T. P., 52, n. ${ }^{\circ} 2,1995$ 

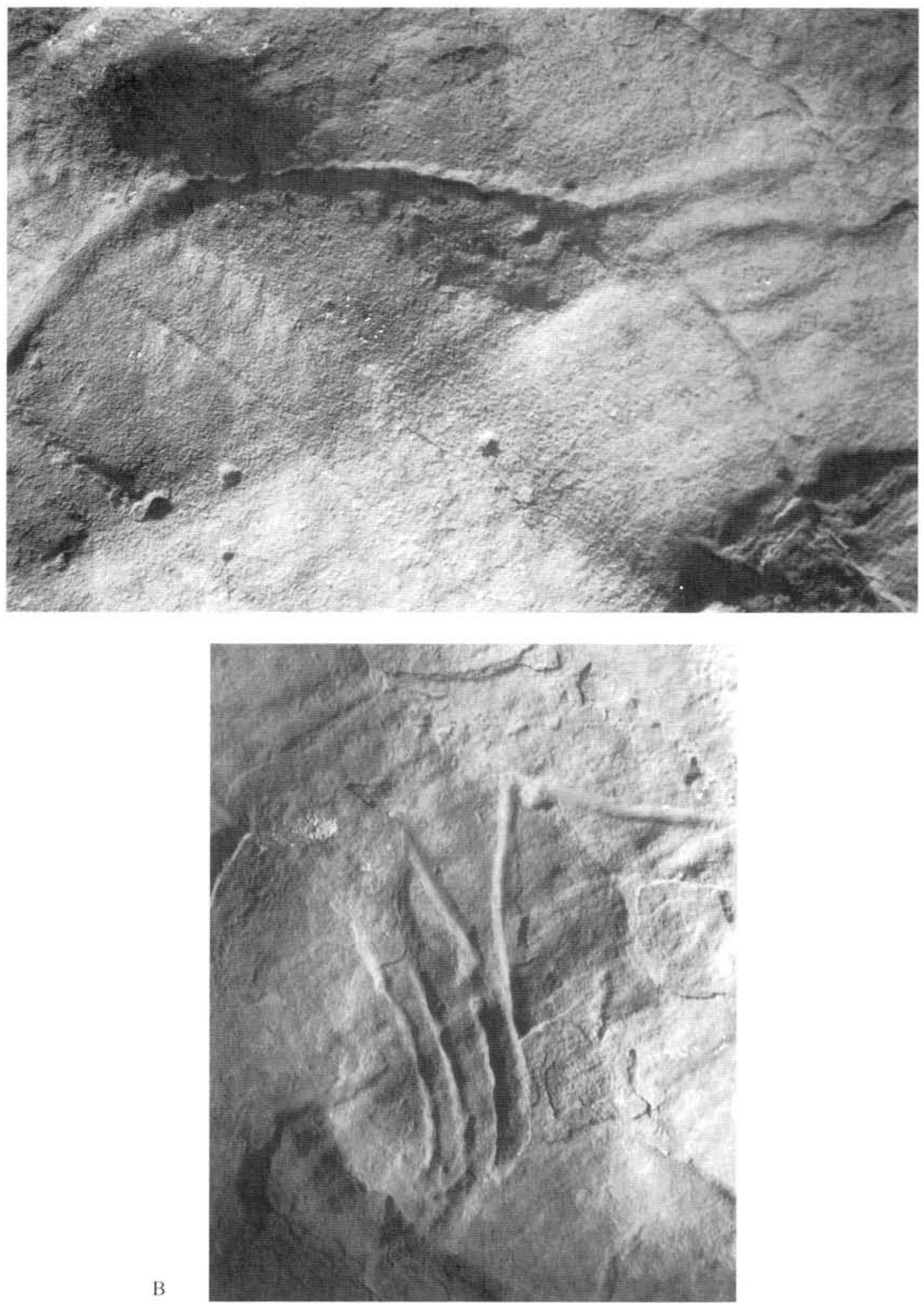

Lám. VI A. La grupa y cola de la gran figura 3 del panel A poseen unas características especiales. Los cuartos traseros están algo perdidos por erosión natural. B. Detalle de la parte anterior de esta espléndida figura .

T. P., 52, n. ${ }^{\circ} 2,1995$ 
agentes naturales. En el interior de la figura aparecen varias cazoletas, algunas de ellas naturales, aunque otras fueron claramente piqueteadas por una acción antrópica antigua, intencionada, ya que poseen una patina idéntica al resto de los surcos. Evidentemente es imposible establecer, sin acudir a técnicas de datación directa, todavía experimentales para los grabados (Dorn, 1983), la contemporaneidad o no de estos motivos piqueteados, que no son recientes, con el équido. Cabe señalar que algunas representaciones de este tipo existen también en relación a la figura 1 del panel B y en la pared de una de las Cuevas de Levante, a la que haremos alusión más adelante y en la que además identificamos otros restos de figuras difícilmente definibles y líneas verticales irregulares.

La perspectiva empleada es biangular, observándose tanto las dos patas delanteras como las traseras en posición de marcha y el resto del cuerpo en perfil absoluto. La pronunciada curva de la línea del vientre nos podría sugerir que estamos en presencia de una yegua preñada, pero en otro apartado abordaremos la problemática de este tipo de équidos. La cabeza, inclinada hacia delante, se sitúa a la misma altura que la línea cérvico dorsal, semejando una posible posición de alerta o movimiento. Por otra parte al encontrarse en una posición ligeramente inclinada hacia la izquierda, la visión general del conjunto nos muestra una figura un tanto deforme. Cuando se observa detenidamente, rectificando el buzamiento, apreciamos un animal en posición de olisquear o bien frenando en un descenso pronunciado.

\section{Panel B}

Este panel, con unas dimensiones más reducidas, se encuentra situado a unos $50 \mathrm{~cm}$. por debajo de la figura 1 del panel $\mathrm{A}$, en un plano diferente $\left(33^{\circ} \mathrm{E}\right)$, y presenta una tonalidad marrón rojiza (HUE 2.5 YR 4/4 - 3/4 según la tabla Munsell), que lo diferencia de la parte superior, además de poseer una textura distinta. Estas circunstancias son las que nos han inducido a individualizar este segundo panel.

\section{Figura 1}

«Protomos» de équido mirando hacia la derecha $(21 \mathrm{~cm}$. de longitud por $20 \mathrm{~cm}$. de anchura, $23 \mathrm{~cm}$. de máxima entre paralelas y con un buzamiento de $18^{\circ} \mathrm{N}$ ) (Lám. VII). La línea cérvico dorsal está incompleta, comenzando tras un desconchón a la altura del cuello y subiendo prácticamente desde la cruz hasta la crinera para finalizar en una de las orejas. Éstas están individualizadas, en posición enhiesta y ligeramente echadas hacia delante. Desde la oreja delantera continúa el trazo hacia la testuz y la frente. El morro redondeado presenta un claro «pico de pato» con una quijada no excesivamente marcada. La línea del pecho arranca desde aquí, sin solución de continuidad y sin que aparezcan las extremidades delanteras. La cabeza no presenta ningún despiece interior.

La figura está realizada con un grabado de tipo lineal en «U» de $21 \mathrm{~mm}$. de anchura media y $3 \mathrm{~mm}$. de profundidad. Además se procedió, en la parte inferior de la quijada, a un rebaje del soporte mediante piqueteado. Esta técnica no la hemos apreciado en los otros motivos del abrigo, a excepción del inicio de la línea cérvico dorsal de la figura 3 del panel A. La consecuencia directa de esta acción es un relieve, cuya intencionalidad no podemos valorar, al quedar resaltada la superficie delimitada por el grabado. Se ha realizado en perspectiva biangular con las dos orejas de frente y la cabeza de perfil.

Por toda la superficie del fondo del abrigo existen otras líneas grabadas con unas características similares, pero de momento, a falta de un análisis más pormenorizado, no hemos conseguido identificar otras representaciones naturalistas que en futuras campañas de documentación se investigarán en profundidad.

En la Cueva del Moro encontramos también pinturas, especialmente centenares de puntuaciones agrupadas en diferentes composiciones ejecutadas en rojo, atribuidas generalmente a fases postpaleolíticas. Su posición tanto en las zonas adyacentes de los paneles que acabamos de describir como fundamentalmente en el piso superior del abrigo, nos hacen pensar que puedan tener una filiación superopaleolítica, pero al no contar con datos objetivos, esperamos poder aportar un análisis más exhaustivo en un futuro próximo.

\section{PARALELOS Y CRONOLOGÍA}

Los paralelos existentes para las representaciones de la Cueva del Moro (Fig. 2), nos sirven a su vez junto con las características estilísticas para establecer un encuadre cronológico compa-

T. P., 52, n. ${ }^{\circ} 2,1995$ 


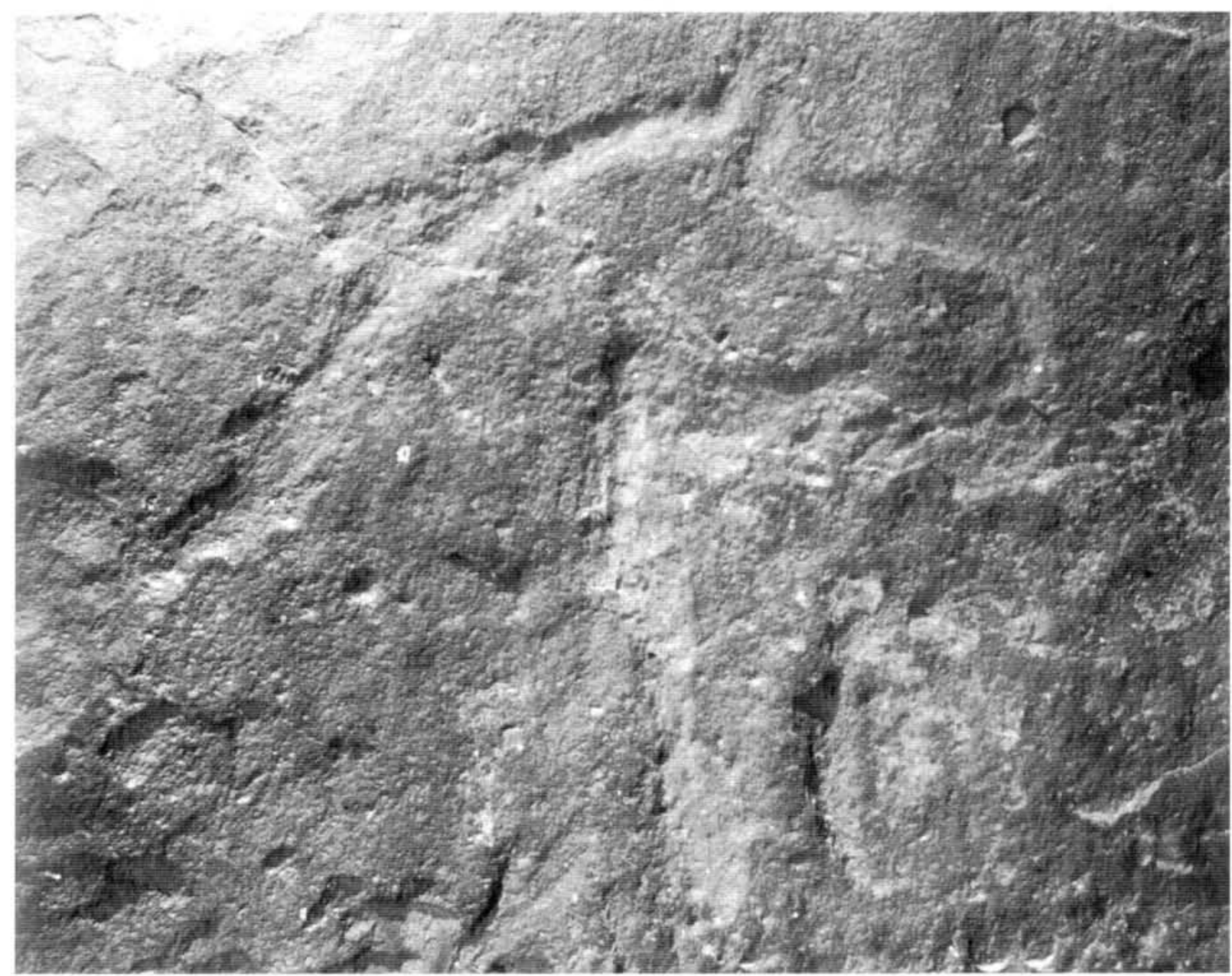

Lám. VII. Protomos de caballo (figura 1 del panel B), se paraleliza con los hallados en La Cueva de Ambrosio. La técnica de piqueteado es diferente a los que se sitúan en la parte superior del conjunto.

rado de estas figuras. No es nuestra intención extendernos en este apartado pues son numerosos los paralelos que podemos encontrar en diversas plaquetas de los niveles solutrenses de la Cova del Parpalló. Algunas de las convenciones de estilo de los dos grandes caballos del Panel A (figs. 1 y 3 ), se encuentran también presentes en los niveles solutrenses iniciales de la cueva valenciana. En concreto se paralelizan con la placa número 104 (Pericot García, 1942: 143), encuadrada en un Solutrense Inferior que presenta un espléndido caballo con una cabeza de reducidas dimensiones y un cuerpo voluminoso, y por otro lado con la número 150 (Pericot García, 1942: 160), hallada en el nivel Solutrense Medio en la que se grabó con una incisión profunda una magnífica cabeza de caballo. La quijada y barboquejo de esta última figura poseen las mismas características que los analizados por nosotros.

Pero no acaban aquí las analogías y limitándonos a Andalucía, cuando se observa por primera vez el gran équido de la Cueva del Moro, inmediatamente se presenta la imagen de la llamada yegua preñada del camarín de la cercana Cueva de la Pileta (Benaoján, Málaga). Si tenemos en cuenta las características morfométricas y estilísticas de los équidos en ella representados, con una posición cronológica bastante clara en un momento del Solutrense Medio (Ripoll Perelló, 1961-1962), argumentada no sólo por los trazos pareados, que también aparecen en 

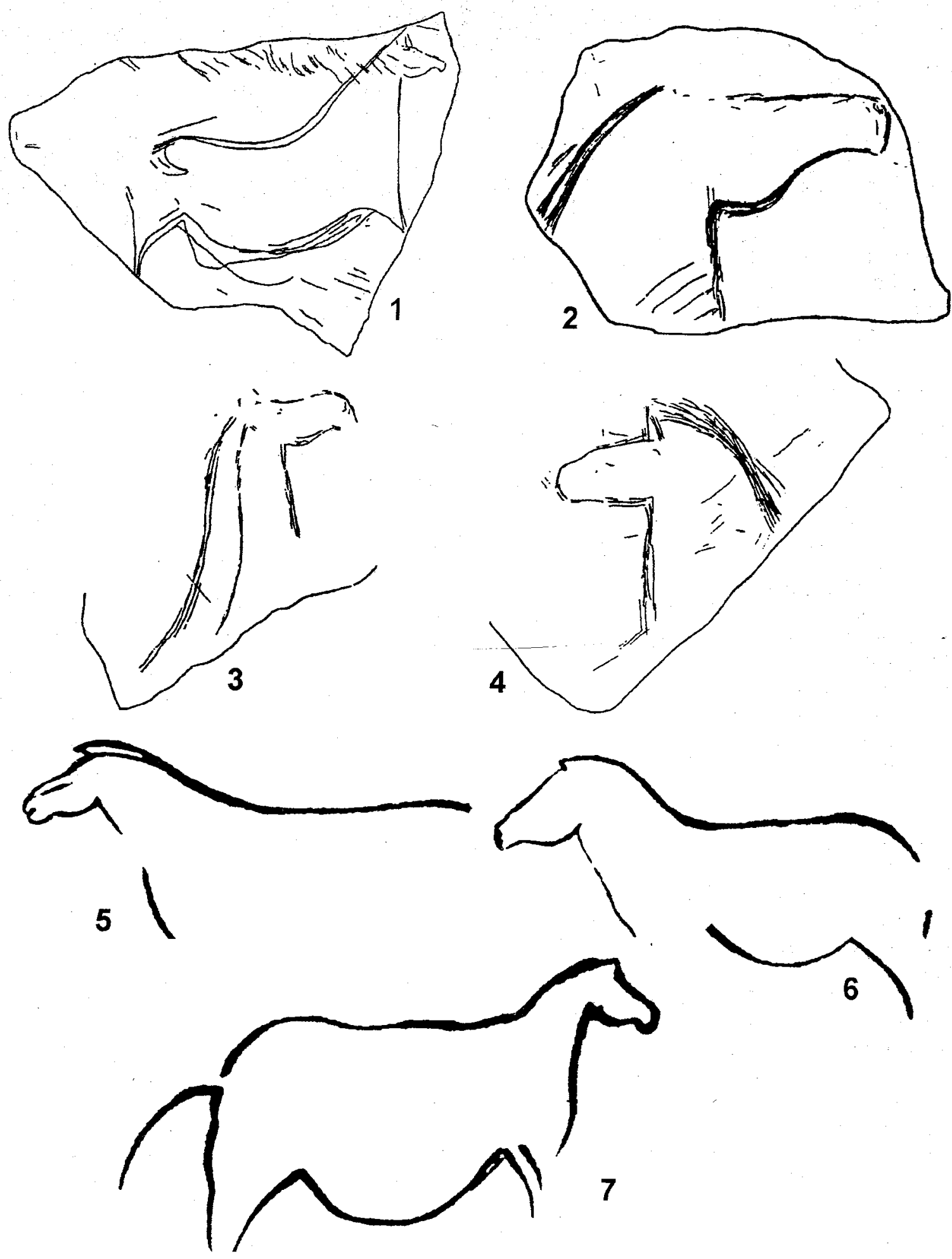

Fig. 2. Conjunto de paralelos referidos en el texto. Las figuras 1 a 4 son plaquetas halladas en diferentes niveles de la Cova del Parpalló (según L. Pericot) y las representaciones 5 a 7 son diferentes équidos de la Cueva de la Pileta (según E. Ripoll). Los paralelos de La Cueva de Ambrosio se pueden consultar en S. Ripoll López et alii (1994).

T. P., 52, n. ${ }^{\circ} 2,1995$ 
otras cavidades, sino también por la forma de representar los volúmenes corporales, podemos comprobar que en líneas generales ambas cavidades están muy próximas en el tiempo y en el estilo.

Por otro lado nos encontramos con el «protomos» de équido del Panel B, que como hemos explicado, se realizó con una técnica diferente a los anteriores. Sus características estilísticas difieren también ya que las proporciones son más equilibradas. Para esta figura podemos establecer un claro paralelismo con los cabalios de La Cueva de Ambrosio, uno de ellos grabado (Panel I) y otro pintado (Panel II) (Ripoll López et alii, 1994), cuya cronología como ya hemos explicado en otras publicaciones para el primero de ellos se sitúa en el Solutrense Superior Evolucionado, mientras que el segundo se encuadra en el Solutrense Superior.

Por otra parte recurrimos de nuevo a la Cova del Parpalló, donde en los niveles tanto del Solutrense Superior (placa 220) (Pericot García, 1942: 175), como en el nivel llamado SolutreoAuriñaciense Final que se corresponde con un Solutrense Superior Evolucionado (placa 256) (Pericot García, 1942: 182), hallamos sendas representaciones de équidos con una cabeza proporcionada, barboquejo marcado y un cuello ancho, como el que hemos hallado en el Moro.

Teniendo en cuenta el conjunto de características hasta ahora expuestas, tanto estilísticas como técnicas, pensamos que el repertorio iconográfico de la Cueva del Moro se realizó posiblemente en dos momentos dentro del horizonte cultural solutrense. Para ello nos basamos por un lado en la diferencias tecnológicas y por otro en los paralelos cuya cronología está bien contrastada. En definitiva, y a modo de hipótesis de trabajo, que deberá comprobarse en un futuro, creemos que el Panel A pudo haberse realizado en un momento inicial del Solutrense, mientras que el « protomos» del Panel B tendría una cronología ligeramente posterior, posiblemente durante el Solutrense final. Los cánones fuertemente estereotipados junto con los convencionalismos nos sitúan pues en un momento pleno del Paleolítico Superior.

\section{INTERPRETACIÓN}

En el estilo III de A. Leroi-Gourhan (1965), la convención domina sobre la representación.
Los análisis que se han realizado para intentar diferenciar las distintas razas de caballos que sirvieron como modelos a los artistas pleistocenos no han aportado ningún dato significativo. Los hombres prehistóricos, como los artistas de todas las épocas, veían con los ojos de su tiempo, no reproducían animales concretos, sino imágenes, en un concepto mucho más genérico.

A pesar de nuestro deseo de presentar un trabajo objetivo, nos vemos obligados a tratar brevemente lo que la Cueva del Moro aporta al significado del arte rupestre paleolítico y entrar en el siempre resbaladizo campo de las hipótesis. Han sido innumerables, casi tantas como investigadores, las teorías que se han esforzado en explicar el porqué de las representaciones parietales. Nosotros únicamente nos referiremos a dos de ellas por ser las que se aproximan más al conjunto analizado y a su posible simbolismo.

Las figuras pintadas o grabadas que han llegado hasta nosotros en un mejor o peor estado de conservación constituyen la documentación más importante que poseemos, relacionada con la evolución del espíritu humano. Las obras imaginativas, abstractas, analíticas o bien con una clara función comunicativa, son los testimonios de unos procesos mentales, conceptuales, estéticos y éticos que han modelado nuestro devenir hasta el estadio actual. Los vestigios descritos, ya sean pictóricos o incisos, son testimonios vivos de la creatividad del hombre prehistórico. $\mathrm{El}$ arte en sí es una interpretación, más que una representación, que nos transmite mensajes implícitos pero no necesariamente informaciones.

La teoría de la magia propiciatoria para la caza, ha sido una de las corrientes más comúnmente admitidas. Ésta es una explicación evidentemente muy racional para un mundo de cazadores-recolectores, pero únicamente reposa sobre algunos elementos muy específicos cuya repartición es muy restringida. En apoyo de esta tesis cabría citar las selectivas representaciones de heridas, armas o trampas.

Por otra parte la hipótesis de la magia de la fecundidad se basa fundamentalmente sobre otros argumentos, pero una de sus bases concretas es la representación de animales grávidos, dado su prominente vientre. Si el motivo de esta teoría es la multiplicación de las especies, es sorprendente que no se encuentren más imágenes de acoplamientos, escenas de parto o de animales jóvenes. A finales del invierno, en el mundo 
animal salvaje, poco antes de los partos, es normal observar numerosas bestias con vientres abultados. ¿No pudo el artista paleolítico inspirarse en ellos sin otro fin que inmortalizarlos fielmente? Pero por otra parte, ¿se trata realmente de animales grávidos? No debemos de olvidar que actualmente, a menudo el pelaje de los animales de regiones frías es mucho más largo que el que puedan presentar sus homólogos estabulados, y esto en cierta forma puede deformar la silueta del animal. Pero en la zona del Campo de Gibraltar y durante el período en el que se grabaron estos équidos, no parece que hiciera un frío especialmente intenso como para provocar el cambio de pelaje adoptando la capa invernal. De ahí que haya que buscar otras explicaciones a la existencia de algunas figuras (El Moro, La Pileta...) con vientres prominentes. El excesivo vientre que reflejan algunos équidos encuadrables en este estilo, desarrollado durante el Solutrense y Magdaleniense, interpretado como hemos visto como determinante del estado de gestación de las yeguas, y como ya propuso R. Lión Valderrábano (1971), podría tratarse en realidad de un estado físico de los équidos debido a un tipo de alimentación basado en grandes masas herbáceas con poca riqueza proteínica. $\mathrm{Al}$ parecer, durante el desarrollo de esta etapa cronocultural finipleistocena, disminuyeron las praderas y aumentaron sensiblemente las masas arbóreas, en un clima templado y húmedo, lo que sin duda favoreció la alimentación arriba reseñada.

\section{EL ARTE PALEOLÍTICO DEL CAMPO DE GIBRALTAR}

En 1991, cuando realizábamos los trabajos de campo correspondientes a una de las campañas del proyecto de investigación arqueológica. «Las manifestaciones rupestres prehistóricas de la zona gaditana», al observar nuevamente los paneles pintados de la Cueva del Tajo de las Figuras (Sierra Momia, Benalup) nos dimos cuenta de la existencia de un gran número de líneas incisas que habían pasado desapercibidas en anteriores investigaciones (Ripoll López et alii, 1991). Se trata de tres motivos figurativos -que interpretamos como cérvido, équido y cáprido- $\mathrm{y}$ otros trazos que no podemos definir formalmente (Fig. 3). Los grabados se localizan en el techo, fondo y pared izquierda, del interior de la cavidad. A pesar de los numerosos investigadores que habían estudiado o visitado la Cueva del Tajo de las Figuras, no hay ninguna referencia en la literatura científica a grabados, que convierten a este importante yacimiento en único y abren nuevas perspectivas a su lectura.

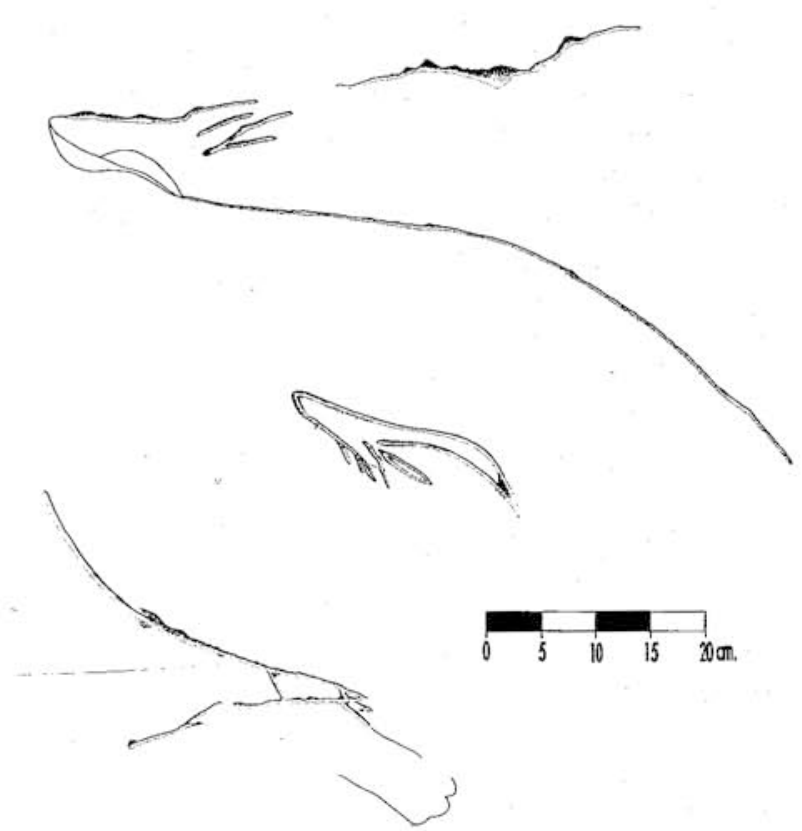

Fig. 3. Grabados paleolíticos de la Cueva del Tajo de las Figuras. En la parte superior se distingue una posible silueta de cabeza de cierva, en el centro una cabeza de cáprido y abajo el protomos de équido que aprovecha un resalte natural de la roca para completar la cabeza.

La primera de las representaciones es una cabeza de cierva orientada hacia la izquierda (62 $\mathrm{cm}$. de longitud por $37 \mathrm{~cm}$. de anchura). Su factura no es espectacular, ya que además de las líneas incisas, también aprovecha en algunas zonas resaltes naturales de la roca. En la parte inicial del cuello, se superpone un pequeño cuadrúpedo $(12 \mathrm{~cm}$. por $7 \mathrm{~cm}$.) de tendencia esquemática, pintado en rojo.

La segunda figura resulta más nítida, dada su posición en un plano subvertical. Hemos identificado un «protomos» de équido dispuesto hacia la derecha (40 cm. de largo por $28 \mathrm{~cm}$. de ancho). Para la realización de la cabeza se aprovechó un resalte natural de la roca, siendo muy evidente la crinera que se encuentra desdoblada en sen- 
dos trazos. El tupé se prolonga por encima de la cabeza que sin duda debió de tener un trazo inciso mucho más profundo, alterado en la actualidad por la existencia en esta zona de un nido de avispas terreras. Al igual que en el caso anterior, en el inicio de la línea cérvico dorsal, se observa otro cuadrúpedo de tendencia esquemática pintado en rojo $(15 \mathrm{~cm}$. de largo por $14 \mathrm{~cm}$. de ancho) claramente superpuesto al surco.

La tercera representación, una cabeza de cáprido con unas proporciones equilibradas (19 $\mathrm{cm}$. de largo por $9 \mathrm{~cm}$. de ancho), se dispone hacia la izquierda. El cuerno, curvo, se prolonga hacia atrás y prácticamente pegada a él se distingue la oreja. También se encuentra infrapuesta a otra figura roja de tendencia esquemática ( 7 $\mathrm{cm}$. de largo por $8 \mathrm{~cm}$. de ancho).

Los posibles paralelos estilísticos nos llevaron a situar estas representaciones en un momento Solutrense «sensu lato» (Ripoll López et alii, 1991). Este encuadre paleolítico queda reafirmado al encontrarse infrapuestas a toda la secuencia pictográfica postpaleolítica, lo cual ratifica su antigüedad, que viene avalada además por la presencia en sus cercanías de dos nuevos asentamientos con industrias solutrenses.

Ya en 1990 una prospección arqueológica superficial (Más Cornellá y Sanchidrián Torti, 1990), realizada con la finalidad de aproximarnos al prácticamente desconocido contexto arqueológico de las pinturas rupestres ejecutadas en los abrigos de Sierra Momia, nos había revelado la existencia de dos yacimientos al aire libre de un interés inesperado, que ofrecían un importante caudal de información y cuya distribución espacial se veía constreñida a áreas muy reducidas. Se trata de la Cubeta de la Paja, dentro del Conjunto rupestre del Tajo de las Figuras, y las Cuevas de Levante. Del conjunto global de las colecciones líticas y su deposición planteamos como hipótesis de trabajo que la funcionalidad de los yacimientos estaría acorde con los patrones de asentamientos estacionales destinados fundamentalmente al abastecimiento de recursos pétreos y su manufactura y los encuadramos cronológicamente en el Solutrense Superior Evolucionado.

En 1991 llevamos a cabo una actuación de urgencia con el fin de diagnosticar y matizar el estado de la cuestión y plantear la intervención más idónea en función de la problemática en torno a la conservación de estos lugares. Un sondeo estratigráfico en las Cuevas de Levante y el análisis de la serie industrial confirmaron el encuadre Solutrense (Ripoll López et alii, 1991).

Durante los trabajos de campo de 1992 (Más Cornellá, 1993) se revisaron y estudiaron un importante número de nuevas cavidades, descubriendo otros grabados cuya filiación paleolítica podría parecer evidente, en tres abrigos rocosos conocidos por sus pinturas postpaleolíticas, la Cueva del Arco, dentro del Conjunto rupestre del Tajo de las Figuras, y las Cuevas de Levante (dos cavidades) - como puede verse coinciden los dos lugares en donde hemos localizado los yacimientos al aire libre con los grabados que aparecen en cavidades cercanas-, cuyo análisis en profundidad aún no hemos finalizado. Puede destacarse, sin embargo, que se trata de unos trazos finos, largos, horizontales y curvados, uno de ellos infrapuesto a diferentes motivos pintados de la Cueva del Arco y restos de figuras difícilmente definibles, unas líneas irregulares trazadas verticalmente, varias cazoletas y un triángulo, en este caso muy próximo a las pinturas, en las Cuevas de Levante. Éstas constituyen un complejo de cavidades (abrigos rocosos) y los grabados se sitúan en la conocida por sus pinturas pospaleolíticas (Breuil y Burkitt, 1929) y en la que se sitúa más hacia el norte.

Algunos autores han puesto en duda la catalogación como paleolíticas de las decoraciones de la Cueva del Tajo de las Figuras (Sanchidrián Torti, 1994). Quizá nuestra interpretación, paralelos tipológicos, puede parecer algo forzada en el caso de alguna figura en concreto, y que existan dos yacimientos al aire libre con industria lítica atribuible al Solutrense a escasos metros de estas cavidades, conjunto rupestre del Tajo de las Figuras y Cuevas de Levante, los únicos conocidos en la zona, que coinciden también con los únicos abrigos que contienen representaciones, no tiene porqué ser un condicionante cronológico estricto. Pero creemos que la infraposición de estos grabados, en treinta y cuatro casos, a figuras de la secuencia pictórica postpaleolítica, sin que nunca ocurra lo contrario, y teniendo ejemplos desde las fases más antiguas a las más recientes en el proceso de ejecución de las pinturas, es indicativo de su antigüedad. Consideramos, también, que no podemos relacionar estas tipologías con ningún motivo postpaleolítico conocido, ni técnica ni estilísticamente y es muy evidente que se trata de auténticos grabados. Esto se hace más patente aún en los trazos no figurativos, que nada tienen que ver con las 
características formas que crea la erosión natural en la arenisca. Teniendo en cuenta, además que el cáprido, la figura más conflictiva en el momento de intentar encontrar paralelos, presenta una forma muy clara, creemos que no podemos concluir más que afirmando que nos hallamos ante un fenómeno muy importante, que no puede olvidarse y que hay que continuar estudiando. Sería absurdo, en plena época postestilística (Lorblanchet y Bahn, 1993), lo cual no quiere decir que el estilo sea irrelevante o inútil (Bahn y Lorblanchet, 1994), marginar estas manifestaciones rupestres, como ha venido sucediendo en la bibliografía científica, dentro de nuestras líneas prioritarias de investigación porque no encajan holgadamente en los estrechos parámetros tecnoestilísticos, formales y de ubicación al uso. Estamos de acuerdo en que hay que ser prudentes, pero también debe aceptarse que con criterios mucho más subjetivos que éstos se han aceptado axiomas que ahora permiten criticar nuestro planteamiento. Recordemos que tan sólo hace algunos años el arte paleolítico al aire libre en la Península Ibérica era considerado algo marginal. Quizá el descubrimiento de la Cueva del Moro y la cada vez más conocida ocupación durante el Paleolítico Superior de las sierras que bordean la antigua Laguna de la Janda pueda hacernos replantear estos temas y considerar nuevas hipótesis de trabajo.

El équido de la Cueva de Palomas 1 (Sierra del Niño, Tarifa) (Fig. 4), de estilo naturalista, quedó enmarcado cronológicamente, a partir de los trabajos de H. Breuil y M.C. Burkitt (1929), al igual que unas bandas de puntuaciones dobles muy próximas a este motivo y del mismo color, en el Paleolítico, relacionándose tipológicamente con algunas representaciones de la Cueva de la Pileta, opinión que compartía también J. Cabré Aguiló (1915). Recordemos, sin embargo, que en este momento se defendía una cronología paleolítica para el arte levantino, con el cual se establecían paralelos de algunas representaciones de otras estaciones de la zona gaditana, aunque ya comenzaba a considerarse, por parte de algunos de los autores que trabajaban en las sierras del Campo de Gibraltar (Cabré Aguiló y Hernández-Pacheco, 1914), una posible atribución postpaleolítica (Cabré Aguiló, 1915; Hernández-Pacheco, 1924) (1). Hace unos años se

(1) Una síntesis sobre el tema puede consultarse en E. Ripoll Perelló, (1986-1987).

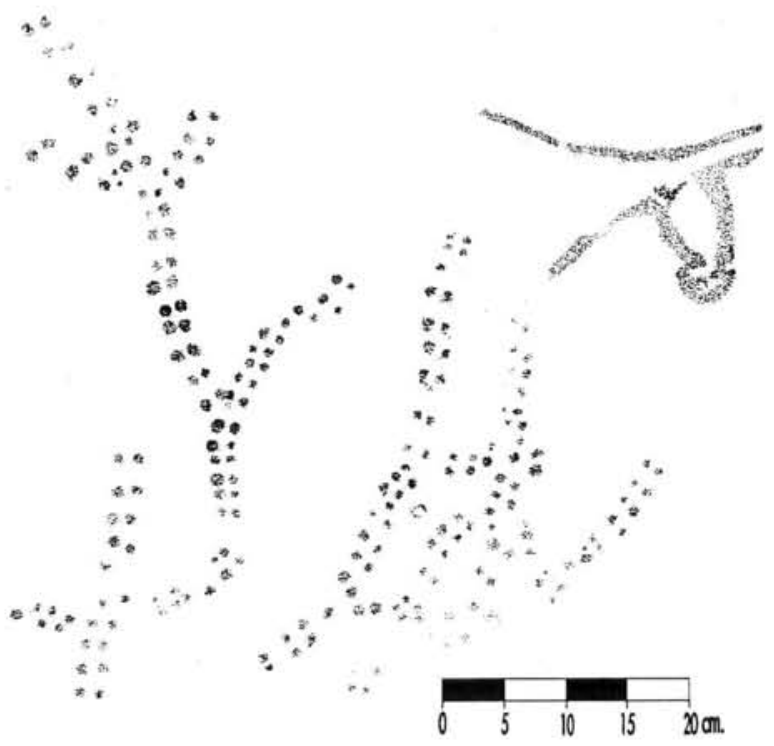

Fig. 4. Panel de la Cueva de Palomas 1, en donde vemos un protomos de équido y un conjunto de puntuaciones pintados en rojo.

planteó un análisis de estos motivos (Sanchidrián Torti y Más Cornellá, e.p.) en el que considerando la técnica de ejecución, el estilo figurativo, el registro gráfico, los patrones topo-icono- gráficos, el marco cultural y otros argumentos se aportaban hipótesis de trabajo en relación tanto de su adscripción a momentos paleolíticos como postpaleolíticos. Aunque entonces no contábamos con estudios directos recientes parecía que la información disponible sobre la figura no permitía comparaciones claras con las manifestaciones paleolíticas conocidas (2). Las puntuaciones, que forman un esquema similar a los ramiformes, y siempre se han queri-

(2) Los calcos, reproducciones y restituciones que en la actualidad podemos disponer sobre esta figura nos muestran un protomos en perspectiva lateral derecha con algunos detalles anatómicos secundarios y líneas de despiece fruto de un trazo modelante, lo que en un principio sintonizaría con el estilo IV de A. Leroi-Gourhan (1965), aunque al mismo tiempo es probable la comparación con zoomorfos solútreo-gravetienses de la Cova de Parpalló (Gandía, Valencia) y la Cueva de la Pileta, pero el «pelaje facial» en base a cortos trazos paralelos se da en exclusividad en determinados animales de un horizonte Magdaleniense Superior de la Cueva de la Pileta, entrando ambos carácteres en clara contradicción estilístico cronológicam. 
do paralelizar a nivel formal con un determinado signo de la Cueva de la Pileta, tampoco parecían tener cabida en unas estructuras topo-iconográficas definidas de forma muy concreta en las cavidades subterráneas de Andalucía (Sanchidrián Torti, inédita). Se concluía diciendo que, mientras no se dispusiera de otros juicios relevantes que convencieran de lo contrario, había que ser reacios a incorporar esta estación rupestre al listado de yacimientos pleistocenos de Andalucía.

Durante 1991 y 1992 realizamos una nueva documentación de la Cueva de Palomas 1 (Más Cornellá 1991, 1993). Cabe decir que se han descubierto un gran número de pinturas postpaleolíticas en la pared frente a la que siempre se había considerado principal (Breuil y Burkitt, 1929). El panel con el «protomos» de équido y las puntuaciones, situado en esta zona, queda, no obstante, claramente diferenciado por su localización. Ambos tipos de representaciones tienen una misma tonalidad roja, aunque aparece con más o menos intensidad en función del lugar que ocupan, ya que el panel ha sufrido una fuerte erosión y la zona en que se encuentra el équido está muy afectada por una gruesa capa de alteración ennegrecida, presentando un aspecto distinto a la parte en donde aparecen las puntuaciones, que tiene también una apariencia desigual debido a una degradación diferencial.

A partir de la nueva reproducción realizada a partir de una documentación muy especializada (fotografías infrarrojas, etc.) puede apreciarse una figura silueteada con un trazo grueso (10-15 mm.). La línea cérvico dorsal sube prácticamente desde la cruz y finaliza en una de las orejas. Éstas están individualizadas, en posición enhiesta y echadas hacia adelante. La testuz es ligeramente convexa, el morro redondeado, se aprecia el barboquejo, y la quijada no está excesivamente marcada. La línea del pecho arranca desde la cabeza. No presenta despiece interior. Creemos que la forma del morro se debe más a un trazo inseguro que al intento de reflejar el ollar. La cabeza mira hacia abajo. Observamos un evidente paralelismo tipológico entre esta representación, la figura 1 del panel B de la Cueva del Moro y uno de los équidos (figuras $1 \mathrm{del}$ panel I y 5 del panel II) de la Cueva de Ambrosio (Ripoll López et alii, 1994), interrelacionable perfectamente con los niveles arqueológicos claramente definidos desde el punto de vista cultural y cronoestratigráfico del mismo yacimiento, como se ha indicado con anterioridad, y con el estilo III-IV de A. Leroi-Gourhan (1965). Sorprende en el «protomos» de la Cueva de Palomas 1 una cierta inflexión entre la testuz y el morro, pero cabe señalar que puede ser debido a un ligero desprendimiento del pigmento en esta parte.

Así pués, sólo unos años más tarde creemos que nuestros planteamientos iniciales pueden reformularse. Las consideraciones del momento referentes a la cultura material en Andalucía Occidental y al arte paleolítico al aire libre en la Península Ibérica han quedado desfasadas. Si nos ceñimos estrictamente al Campo de Gibraltar cabe decir que se han localizado cinco nuevas cavidades con manifestaciones artísticas paleolíticas (Cuevas del Tajo de las Figuras, del Arco, de Levante 1 y 2 y del Moro) y dos asentamientos al aire libre (Cuevas de Levante y Cubeta de la Paja), que deben sumarse a los escasos yacimientos conocidos hasta entonces, la Cueva de Palomas 1, el nivel B de Gorham's Cave (Waechter, 1953, 1964) y las pinturas, aunque problemáticas, de St Michel's Cave (Breuil, 1921, 1922), aparte de los recientes descubrimientos de Gibraltar (Giles Pacheco et alii, 1994).

En cuanto a las bandas de puntuaciones (hemos contabilizado 231 puntos) (Lám. VIII) cabe decir que adoptan una morfología difícilmente definible. En su momento H. Breuil y M.C. Burkitt (1929: 53) sugirieron su posible adscripción al arte paleolítico: «It is possible that the punctuations just mentioned, apparently so out of place in the neolithic surroundings of the province of Cádiz and reminiscent of the dotted red figures of the above cave (Cueva de la Pileta), are also palaeolithic». Curiosamente este tipo de motivos (puntuaciones, aisladas o creando diferentes tipos de composiciones, muy próximas a los signos del mundo de los cazadoresrecolectores del Pleistoceno Superior Final) aparecen abundantemente tanto en la Cueva del Moro como en la de Palomas 1 (y también en las primeras fases pictóricas de la Cueva del Tajo de las Figuras), aunque no creemos que puedan generalizarse conclusiones, ya que agrupaciones de puntos formando diferentes estructuras son un tema frecuente en la pintura esquemática de la Península Ibérica, ampliamente ejecutado en otros yacimientos con representaciones postpaleolíticas de la zona que nos ocupa. 


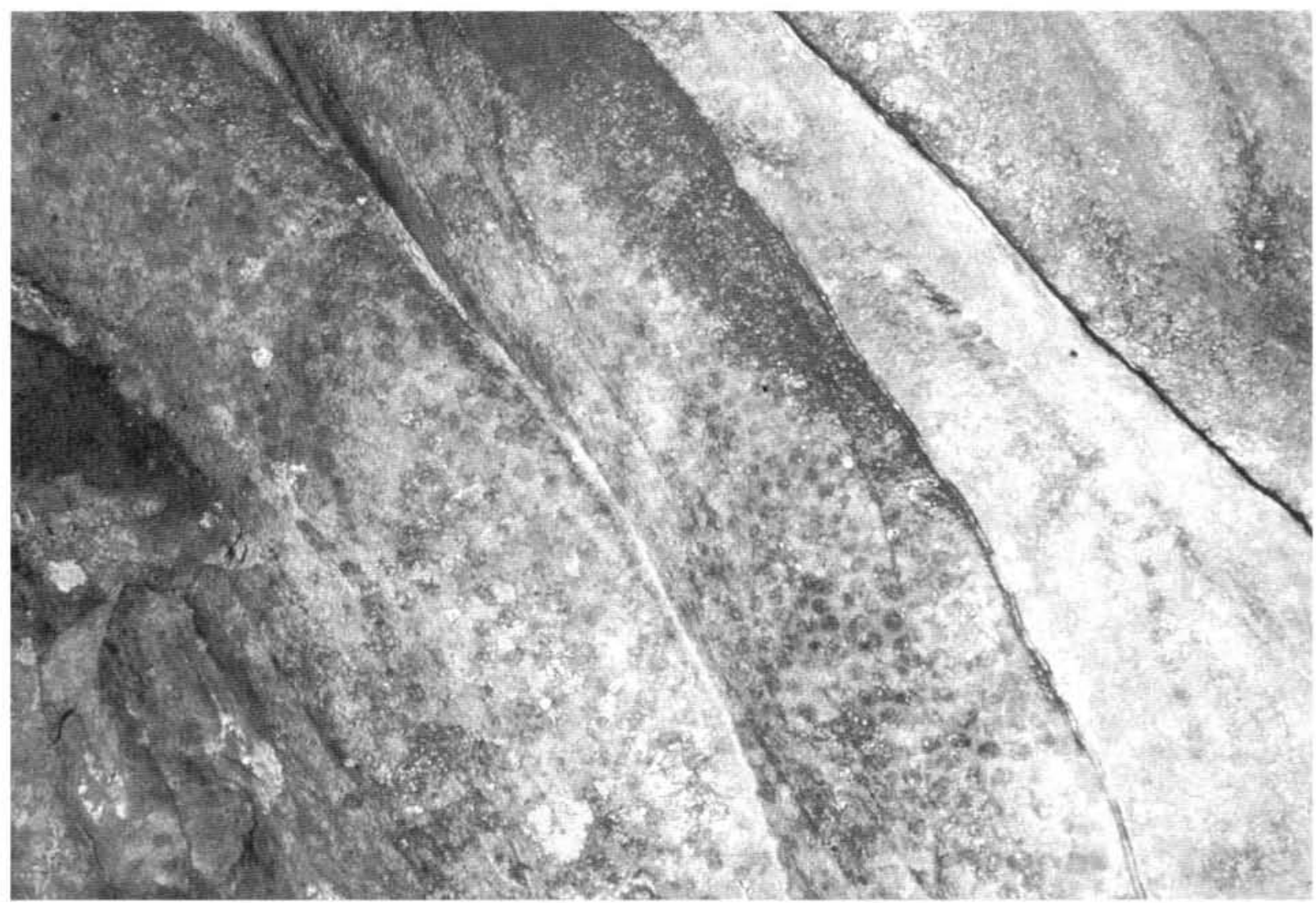

Lám. VIII. "Tectiforme" a base de puntuaciones rojas localizadas en el piso superior de la Cueva del Moro.

En relación a la cronología relativa de una de las figuras de la Cueva de Levante 1 podemos avanzar algunos datos. La secuencia de procesos que se desprenden del análisis de la estratigrafía que ofrece el sondeo realizado en las Cuevas de Levante (estudio geoarqueológico realizado por J.F. Jordá Pardo, que se dará a conocer dentro de la memoria científica de esta actuación arqueológica) puede articularse en cinco fases. Fase 1: Génesis de la cavidad en algún momento indeterminado del Pleistoceno, en cualquier caso anterior a los últimos estadios del Pleistoceno Superior. Fase 2: Ocupación del abrigo (1 y 2) por grupos humanos del Paleolítico Superior, disponiéndose los restos tecnoculturales sobre sedimentos producto de la alteración de las areniscas que constituyen el abrigo. La industria recuperada corresponde al Solutrense Superior Evolucionado. Este dato sitúa la fase de ocupación humana y del relleno del abrigo con materiales antrópicos hacia los últimos estadios del Pleistoceno Superior. Fase 3: Desarrollo de pro- cesos de arroyada difusa de muy baja energia responsables de la génesis del nivel 1 (Ripoll López et alii, 1991). Fase 4: Desmantelamiento del depósito que rellenaba parcialmente el abrigo y distribución por la pendiente de los materiales arqueológicos, actuando como mecanismo de transporte la arroyada difusa, con una energía superior a la de la fase 3 , dando lugar a los depósitos del nivel 2 (en las paredes del abrigo 1 observamos marcas de sedimento a una altura sobre el suelo actual que varía entre 100 y $60 \mathrm{~cm}$. y que indican la existencia de un antiguo relleno que, al menos, alcanzó esta cota en su interior). Estos procesos se situarían probablemente en el tránsito Pleistoceno Superior-Holoceno, en un momento de cierta pluviosidad detectada en otros yacimientos andaluces (Jordá Pardo et alii, 1990). Fase 5: Infiltración gravitacional de sedimentos finos en los niveles más profundos (nivel 1), removilización del tramo superior de los depósitos resedimentados en la fase 3 por procesos de bioturbación (nivel 3 ) y desarrollo de acti- 
vidades antrópicas superficiales durante el Holoceno hasta la actualidad.

En la zona descrita, a $70 \mathrm{~cm}$. del suelo y totalmente cubierto por las marcas de sedimento, observamos un triángulo equilátero inciso, que debemos situar cronológicamente en el momento de formación del relleno (proceso de origen natural y cultural) o en una fase anterior. Recordemos que en la secuencia de la Cova de Parpa110 el triángulo está escasamente representado (nueve sujetos, un 0,09\%), aunque tiende a aparecer concentrado en el Solutrense Medio y Superior (Villaverde Bonilla, 1994). En este mismo abrigo hay una banda de veintiséis trazos verticales paralelos pintados en rojo que queda al margen de las marcas de sedimento, en una parte algo más alta (unos centímetros) de la pared.

Llegados a este punto debemos plantearnos si los grabados del suelo de la Cueva del Arco, que dimos a conocer hace unos años y situamos en fases avanzadas de la Prehistoria Reciente no cabrían más holgadamente desde una perspectiva estrictamente tipológica en el Paleolítico Superior. En aquel momento concluíamos considerando «la necesidad de estudiar los conjuntos rupestres globalmente, sin excluir aspectos que en un primer momento no parezcan importantes» (Mas Cornellá, 1986-1987: 252) y recogíamos la opinión de H. Breuil (1920: 322) referente a determinadas figuras, generalmente grafitos, que en algunos casos estaban en lugares próximos a pinturas o en el mismo panel: «manifestations artistiques en partie mal datées; néanmoins, leur antiquité considérable étant certaine, il m'a paru intéressant de les donner à la publicité, afin que d'autres personnes rencontrant des faits analogues, leur accordent quelque importance, et que de la compilation des documents, sorte quelque jour une donnée plus précise sur leur attribution à une civilisation déterminée». «Se trata de dos representaciones que definimos como trazos paralelos, «barras de tres a seis milímetros de grosor y entre dos y tres de profundidad que configuran un triángulo cortado por una incisión en uno de sus lados», y una retícula, «conjunto de líneas de un milímetro a un centímetro de grosor y entre un milímetro y tres de profundidad, ejecutadas irregularmente» (Más Cornellá, 1986-1987: 249). Algunos signos de la secuencia de la Cova de Parpalló con una tendencia $\mathrm{u}$ orientación triangular, bandas o haces de líneas paralelas y bandas de trazos cor- tos paralelos oblicuos en serie, corresponden respectivamente al Solutrense Inferior, Solutrense Superior y Magdaleniense Antiguo B. Las retículas aparecen documentadas en prácticamente todos los períodos (Villaverde Bonilla, 1994). Se justificaría también de este modo, en cierta forma, la cronología paleolítica para el haz de líneas verticales irregulares paralelas de la Cueva de Levante 2, que no desentona, en conjunto, con los demás grabados de la zona.

En cuanto a las cazoletas, sorprende también encontrarlas tanto en la Cueva de Levante 2 como en la del Moro, asociadas aquí con la figuras 3 del panel A y 1 del B. No es un motivo habitual dentro del arte postpaleolítico de la zona gaditana. Nos preguntamos si no sería el elemento grabado equivalente a la puntuación pintada. No vamos a entrar en más consideraciones sobre la pintura rupestre del área, sólo precisar que al igual que éste (puntuaciones) podrían detectarse temas paleolíticos o de tradición paleolítica - este sustrato se define cada vez como más importante- en unas manifestaciones caracterizadas por su originalidad estilística, como hemos remarcado numerosas veces en otros artículos.

A propósito de la aclaración de P. Graziosi (1968), en la que sugiere que la provincia mediterránea con todas sus características de estilo no constituye más que una fase de la evolución del arte paleolítico, es decir la fase más reciente de este arte podría estar precedida por la difusión de otro arte de origen franco-cantábrico, el cual nos ofrece, en algunos casos, unas características de sabor arcaico. La provincia mediterránea podría constituir una evolución independiente en relación a la del arte clásico de Francia y España. Nosotros creemos que las características estilísticas, técnicas y morfométricas de las representaciones figurativas de la zona andalu$\mathrm{za}$, no deben de incluirse en este mundo de transición que proponía el investigador italiano, sino que deben estar incluidas por méritos propios dentro de las corrientes pictóricas más clásicas tal como opinaba en su momento P. Graziosi.

La Cueva del Moro viene a reafirmar la importancia del Paleolítico Superior en Andalucía Occidental y añade un nuevo yacimiento a la reducida lista de estaciones al aire libre (o en abrigo) con pinturas o grabados conocidas hasta ahora en la Comunidad Autónoma: Cueva de Ambrosio (Vélez Blanco, Almería) (Ripoll López et alii, 1994), Piedras Blancas (Escúllar, 
Almería) (Martínez García, 1986-1987) y Cuevas del Tajo de las Figuras (Ripoll López et alii, 1991), del Arco y de Levante (Benalup, Cádiz) (Más Cornellá, 1993), sin olvidar la Cueva de Palomas 1 (Tarifa, Cádiz) (Breuil y Burkitt, 1929; Leroi-Gourhan, 1965; Breuil, 1974; Fortea Pérez, 1978; Santiago Vílchez, 1979-1980). Los numerosos hallazgos que se están produciendo en la zona objeto de estudio y los que aún faltan por conocer, nos indican que hay que ser más flexibles en cuanto a los planteamientos. De ahí la necesidad de estar abierto a las novedades que se producen y prescindir de esquemas o patrones iconográficos rígidos y subjetivos que tantas veces se han formulado para nuestro arte paleolítico y que dificultan la comprensión de nuevos rasgos o elementos y en definitiva una valoración más global.

Además, tenemos que tener en cuenta que a este hecho se le une la singularidad de que se trata del arte rupestre más meridional de Europa. Esto plantea una cuestión importante y es la de saber si a lo largo de los milenios en que se desarrolló el arte pleistoceno, las ideas intrínsecas del mismo llegaron a cruzar el Estrecho de Gibraltar. Hasta ahora no se conoce ninguna estación, sin duda por la falta de prospecciones sitemáticas, pero creemos, a la luz de los recientes hallazgos al aire libre, que la investigación en el vecino país alauita debería dirigirse en este sentido.

\section{BIBLIOGRAFÍA}

BAHN, P.G. y LORBLANCHET, M. (1994): «El arte rupestre: ¿La era post-estilística?, o: ¿A dónde vamos de aquí?». Boletín de la Sociedad de Investigación del Arte Rupestre de Bolivia, 8: 23-27.

BREUIL, H. (1920): «Miscellanea d'art rupestre I». Boletín de la Real Sociedad Española de Historia Natural, XX: 232-333, 11 figuras.

- (1921): «Nouvelles cavernes ornées paléolithiques dans la province de Málaga». L'Anthropologie, XXXI: 239253,11 figuras.

- (1922): «Palaeolithic man at Gibraltar: new and old facts». The Journal of the Royal Anthropological Institute of Great Britain and Ireland, LII: 46-54, 2 figuras.

- (1974): «Quatre cents siècles d'art pariétal. Les cavernes ornées de l'age du renne». Editions Max Fourny Art et Industrie. Paris (segunda edición), 413 págs., 531 figuras.

BREUIL, H. y BURKITT, M.C. (1929): «Rock paintings of Southern Andalusia. A description of a Neolithic and Copper Age art group». Clarendon Press. Oxford, XII, 88 págs., 54 figs., XXXIII láminas.
CABRÉ AgUILÓ, J. (1915): «El arte rupestre en España (regiones septentrional y oriental)». Memorias de la Comisión de Investigaciones Paleontológicas y Prehistóricas, 1, 229 págs., 104 figs., XXXI láms., I tabla, ilustraciones.

CABRÉ, J. y HeRnÁNDEZ-PACHECO, E. (1914): «Avance al estudio de las pinturas prehistóricas del extremo Sur de España (Laguna de la Janda)». Trabajos de la Comisión de Investigaciones Paleontológicas y Prehistóricas, 3, 35 págs., 6 figs., XIII láminas.

DORN, R.I. (1983): «Catio-Ratio Dating: A New Rock Varnish Age-Determination Technique». Quaternary Research, 20: 49-73, 8 figuras.

Fortea PÉREZ, F.J. (1978): «Arte paleolítico del Mediterráneo español». Trabajos de Prehistoria, 35: 99-149, 25 figs., ilustraciones.

Giles Pacheco, F.; Santiago Pérez, A.; Gutiérrez López, J.M.; MATA Almonte, E. y Aguilera RodríGUEZ, L. (1994): «Nuevas aportaciones a la secuencia del Paleolítico Superior en Gibraltar y su enmarque en el contexto suroccidental de la Península Ibérica». En J. Rodríguez Vidal, F. Díaz del Olmo, C. Finlayson y F. Giles Pacheco (eds.): Gibraltar during the Quaternary, Asociación Española para el Estudio del Cuaternario (AEQUA Monografías, 2), Sevilla: 91-110.

Grazıosi, P. (1968): «L'art paléo-épipaléolithique de la Province Méditerranéenne et ses nouveaux documents d'Afrique du Nord et du Proche Orient». Simposio Internacional de Arte Rupestre (Barcelona, 1966) Barcelona: $265-271,4$ figuras.

HERNÁNDEZ-PACHECO, E. (1924): «Las pinturas prehistóricas de las Cuevas de la Araña (Valencia). Evolución del arte rupestre de España». Memorias de la Comisión de Investigaciones Paleontológicas y Prehistóricas, 34, 221 págs., 86 figs., XXIV láms.

JORdÁ PARDo, J.F.; Aura TORTOSA, J.E. y JORdÁ CERdA, F. (1990): «El límite Pleistoceno-Holoceno en el yacimiento de la Cueva de Nerja (Málaga)». Geogaceta, 8: 102-104.

LEROI-GOURHAN, A. (1965), «Préhistoire de l'art occidental». Edit. Mazenod. París, 319 págs., con láminas y cuadros.

LION VALDERRÁBANO, R. (1971): "El caballo en el arte Cántabro-aquitano. Estudio estilístico, hipométrico y faneróptico de las representaciones paleolíticas». Publicaciones del Patronato de las Cuevas Prehistóricas de la provincia de Santander, 93 págs. 13 figuras.

LORBLANCHET, M. y BAHN, P.G. (eds) (1993): «Rock Art Studies: The Post-Stylistic Era, or Where do we go from here?». Papers presented in symposium $A$ of the 2nd AURA Congress. Cairns 1992. Oxbow Monograph, 35. Oxbow Books Oxford, 204 páginas.

Martínez García, J. (1986-1987): «Un grabado al aire libre en Piedras Blancas (Escullar, Almería)». Ars Praehistorica, V-VI: 49-58, 8 figuras.

MAS CORNELLÁ, M. (1986-1987): «Los grabados de la Cueva del Arco (Conjunto rupestre del Tajo de las Figuras) y del Abrigo del Tajo de Albarianes (Medina Sidonia, Cádiz)». Ars Praehistorica, V-VI: 247-252, 6 figuras.

- (1991): «Documentación e investigación de las manifestaciones artísticas de las Cuevas de Palomas, Abri-

T. P., 52, n. ${ }^{\circ} 2,1995$ 
gos de Bacinete y Conjunto rupestre del Tajo de las Figuras (Cádiz)». Anuario Arqueológico de Andalucía, 1991. II: Actividades Sistemáticas. Informes y Memorias: $99-104,12$ figs.

- (1993): «Proyecto: Las manifestaciones rupestres prehistóricas de la zona gaditana. El arte prehistórico en las sierras del Campo de Gibraltar». Investigaciones arqueológicas en Andalucía, 1985-1992. Proyectos. Dirección General de Bienes Culturales. Consejería de Cultura y Medio Ambiente de la Junta de Andalucía, Huelva: 263-271, 1 figura.

Mas Cornellá M.; Jordé Pardo, J.F.; Cambra SÁNCHEZ, J.; MAS Riera, J. y Lombarte CARRERA, A. (e p.): «La conservación del arte rupestre en las sierras del Campo de Gibraltar. Un primer diagnóstico». Espacio, Tiempo y Forma. Serie I: Prehistoria y Arqueología, 7.

MAs Cornellá, M. y SANChIDRIÁN TORTI, J. L. (1990): «Proyecto de investigación arqueológica Las manifestaciones rupestres prehistóricas de la zona gaditana. 1990: Prospección arqueológica superficial en las Cuevas de Levante y el Conjunto rupestre del Tajo de las Figuras (Sierra Momia)». Anuario Arqueológico de Andalucia, 1990. II: Actividades Sistemáticas. Informes y Memorias: $359-370,13$ figs.

mas Cornellá, M.; Torra Colell, G.; Ripoll lópez, S.; GaVilán CEBAllos, B.; Vera Rodríguez, J.C. y JORDÁ PARDO, J.F. (1995): «El poblamiento prehistórico en las sierras próximas a la antigua Laguna de la Janda». En J.M. Recio Espejo, J.C. Castro Román y A. Santiago Pérez (eds): Jornadas de Campo en la Depresión de la Janda (Cádiz). 19, 20 y 21 de mayo de 1995. Asociación Española para el Estudio del Cuaternario (AEQUA - GAC). Córdoba: 92-104, 5 figuras.

Pericot García, L. (1942): La cueva del Parpalló (Gandía). Consejo Superior de Investigaciones Científicas, Instituto Diego Velázquez. Madrid, 349 págs., 650 figs. y XXXII láminas.

Ripoll López, S.; Mas Cornellá, M. y Perdigones Moreno, L. (1991): «Actuaciones de urgencia en las Cuevas de Levante y Cubeta de la Paja (Sierra Momia, Benalup, Cádiz)». Anuario Arqueológico de Andalucía, 1990. II: Actividades Sistemáticas. Informes y Memorias: 105-110, 7 figuras.

Ripoll López, S.; MAs Cornellá, M. y Torra Colell, G. (1991), «Grabados paleolíticos en la Cueva del Tajo de las Figuras (Benalup, Cádiz)». Espacio, Tiempo y Forma. Serie I: Prehistoria y Arqueología, 4: 111-126, 9 figuras.

Ripoll López, S.; MuÑoz, F.J.; Pérez, S.; MuÑIz, M:, Calleja, F.; Martos, J.A.; López, R. y Amaya, C. (1994): «Arte rupestre paleolítico en el yacimiento solutrense de la Cueva de Ambrosio (Vélez Blanco, Almería)». Trabajos de Prehistoria, 51: 21-39, 6 figs., 6 láminas.

RiPOll Perelló, E. (1961-1962): «La cronología relativa del Santuario de la Cueva de la Pileta y el arte solutrense». Libro homenaje al profesor Cayetano de Mergelina, Universidad de Murcia: 739-751, 6 figuras

- (1986-1987): «A los veinticinco años de la muerte del Abate Henri Breuil». Ars Praehistorica, V-VI: 13-19, ilustraciones.

SANCHIDRIÁN TORTI, J.L. (1994): «Arte paleolítico de la zona meridional de la Península Ibérica». Complutum, 5: 163-195, 10 figs., cuadros.

Inédita, Arte paleolítico en Andalucía. Corpus y análisis topográfico, estilístico y secuencial. Tesis doctoral Universidad de Málaga, 1990

SANChidRián TORTI, J.L. y Mas CORnellá, M. (e.p.): «Discusiones en torno al considerado arte paleolítico del Campo de Gibraltar (Cádiz)». II Congreso Internacional El Estrecho de Gibraltar. Ceuta, noviembre de 1990. Universidad Nacional de Educación a Distancia, Madrid.

SANTiago Vílchez, J.M. (1979-1980): «La Cueva de las Palomas en el arte paleolítico del Sur de España». Boletín del Museo de Cádiz, II: 5-11, III láminas.

VILlaverde Bonilla, V. (1994): "Arte paleolitico de la Cova del Parpalló. Estudio de la colección de plaquetas y cantos grabados y pintados». Servei d'Investigació Prehistòrica de la Diputació de València, Valencia (2 volúmenes).

WAECHTER, J. (1953): «The excavation of Gorham's cave and its relation to the prehistory of Southern Spain». Archivo de Prehistoria Levantina, IV (Homenaje a D. Isidro Ballester Tormo): 21-24.

- (1964): «The Excavation of Gorham's Cave, Gibraltar, 1951-54». Bulletin of the Institute of Archaeology, 4: 189-221, 9 figs., lám. XIII. 